The Role of 2-Oxoglutarate and Iron-Dependent Oxygenase Domain Containing-1 (OGFOD1) in Hypoxia Survival and its Effects on the Active SREBP1

\author{
By \\ Xuena Yang, B.Sc.H.
}

A thesis submitted to

the Faculty of Graduate Studies and Research

in partial fulfillment of

the requirements for the degree of

Masters of Science

Biology Department

Ottawa-Carleton Institute of Biology

Carleton University

Ottawa, Ontario

August 2009

Copyright (C) Xuena Yang 2009 
The undersigned hereby recommend to

the Faculty of Graduate Studies and Research

acceptance of this thesis

\title{
The Role of 2-Oxoglutarate and Iron-Dependent Oxygenase Domain Containing-1 (OGFOD1) in Hypoxia Survival and its Effects on the Active SREBP1
}

\author{
By
}

Xuena Yang, B.Sc.H.

in partial fulfillment of the requirements

for the degree of Masters of Science

Chair, Department of Biology

Thesis Supervisor

Carleton University

ii 


\section{Abstract}

Human 2-oxoglutarate- and iron-dependent oxygenase domain containing 1 (hOGFOD1) is an uncharacterized protein that contains a PKHD (prolyl/lysyl hydroxylase) domain that may act as a cellular oxygen sensor. hOGFOD1 was found to contain a putative oxygen degradation domain (ODDD), similar to that found in the transcription factor Hypoxia-Inducible Factor (HIF). We examined protein turnover of hOGFOD1 in the presence of cycloheximide in human embryonic kidney (HEK293A) cells. hOGFOD1 turnover did not change during treatment of cells with normoxia or hypoxia $\left(1 \% \mathrm{O}_{2}\right)$. Exposure of cells to hypoxia resulted in no significantly changes observed in OGFOD1 gene expression as well as no significant accumulation of OGFOD1 protein. Hydroxylation of hOGFOD1 ODD may, however, affect its interaction with, and modification of, the sterol response element binding protein 1 (SREBP1). OGFOD1 in fission yeast (Schizosaccharomyces pombe) (Ofd1) has been shown to mediate the degradation of the SREBP1 equivalent (Sre1), regulated by the binding of Negative Regulator of Ofd1 (Nro1), in an oxygen-dependent manner. Unlike Ofd1 in fission yeast, it was found that OGFOD1 does not affect the stability of either the precursor SREBP1 (SREBP1P) or the active form of SREBP1 (SREBP1N). According to the results, the PKHD domain of OGFOD1 does not play a role in the formation of SREBP1N from its precursor SREBP1P or the stability of SREBP1N. We also did not find any evidence that OGFOD1 interacts with SREBP1N in coimmunoprecipitation studies. Further studies will mutate the active site of OGFOD1 and examine the effects on SREBP1 as well as knockdown of OGFOD1. 


\section{Acknowledgements}

First off, I want to give a huge thank you to my supervisor Dr. William Willmore for all of his guidance and support. His optimistic attitude and passion for science has been an incredible influence on my outlook on this vast and always-changing field. If it weren't for his persistent encouragements to push me along, I would have given up a long time ago. The many hours discussing results and the time he put into editing this thesis is enormously appreciated.

I am also extremely grateful to have Dr. Micheline Paulin-Levasseur and Dr. Tim Xing on my committee, and Dr. Ashkan Golshani and Dr. John Vierula for being on my thesis defence committee.

Next I would like to thank all the lab members that have been with me for the last two years, especially to Nikolai Chepelev who has always been there to help and support me.

Not to be forgotten, my family members were always willing to give me the support I needed. When I arrived to Canada, my aunt's family took care of me; I would like to thank them for helping me through my times of need. Without their nurture, I would not have been able to achieve my goals in Canada. I would also like to thank my aunt's friend: the Gan family. They provided a relaxing and comfortable environment for me to stay in, and to finish my thesis in.

I am happy to be on the path of fulfilment to my dream. I want to thank my father and mother and Hui - my family truly inspired me in times of discouragement and manoeuvred me through to the path of success. 


\section{TABLE OF CONTENTS}

1. ABSTRACT

2. ACKNOWLEDGEMENTS

3. TABLE OF CONTENTS

4. LIST OF FIGURES AND TABLES

ix

5. LIST OF ABBREVIATIONS

6. INTRODUCTION

6.1. Hypoxia 1

6.2. Hypoxia Inducible Factor (HIF) 2

$\begin{array}{ll}\text { 6.3. Prolyl hydroxylases } & 7\end{array}$

6.4. Sterol Regulatory Element Binding Protein-1 (SREBP1) 19

6.5. Protein modification of SREBPs regulate their activities 21

6.6. SREBP1 and hypoxia 26

$\begin{array}{lll}\text { 6.7. } & \text { Sre1N and Ofd1 in yeast cells } & 27\end{array}$

6.8. 2-Oxoglutarate and iron-dependent oxygenase domain containing-1 (OGFOD1) in mammalian cells

6.9. Hypothesis 29

7. MATERIALS AND METHODS 38

7.1. Database search for the LXXLAP sequence 38 
7.2. Chemicals and cell culture

7.3. MTT assay

7.4. Human OGFOD1 cloning

7.5. Site-directed mutagenesis

7.6. Transient transfections

7.7. Real-time RT-PCR

7.8. Whole cell extract preparation 50

$\begin{array}{lll}\text { 7.9. Western blot analysis } & 47\end{array}$

7.10. Coimmunoprecipitation assay $\quad 48$

$\begin{array}{ll}\text { 7.11. Statistical analysis } & 49\end{array}$

$\begin{array}{llr}\text { 8. RESULTS } & 50\end{array}$

8.1 Database search for the LXXLAP subsequence 50

8.2 Changes in Endogenous OGFOD1 protein levels in response to hypoxia 52

8.3 OGFOD1 gene expression level in response to hypoxia 55

8.4 Cloning, tagging and expression of recombinant OGFOD1 58

8.5 Cell viability with cycloheximide treatment 58

$\begin{array}{lll}\text { 8.6 Protein synthesis inhibition studies } & 63\end{array}$

8.7 Effects of normoxia and hypoxia on recombinant wildtype and mutant OGFOD1

8.8 Protein expression of mature and precursor forms of SREBP1 with overexpression of wildtype and P370A mutant OGFOD1 under hypoxia.

8.9 Expression of mature and precursor forms of SREBP1 protein with 
overexpression of wildtype OGFOD1 under treatment with prolyl hydroxylase $\begin{array}{ll}\text { inhibitors } & 75\end{array}$

8.10 The potential interaction between SREBP1 and OGFOD1 76

$\begin{array}{lll}8.11 & \text { Novel proteins could interact with OGFOD1 }\end{array}$

$\begin{array}{ll}\text { 9. DISCUSSION } & 82\end{array}$

$\begin{array}{lll}9.1 & \text { Putative hydroxylation site search } & 82\end{array}$

9.2 Human Embryonic Kidney (HEK293) cells as a model system 83

$\begin{array}{llr}9.3 & \text { Cell viability } & 84\end{array}$

9.4 OGFOD1 mRNA and protein expression under hypoxic conditions in HEK293A $\begin{array}{ll}\text { cells } & 85\end{array}$

$\begin{array}{lll}9.5 & \text { SREBP1 and OGFOD1 } & 87\end{array}$

$\begin{array}{lll}9.6 & \text { Future directions } & 90\end{array}$

10. REFERENCES 93 


\section{LIST OF FIGURES AND TABLES}

Figure 6.1: The structure of the heterodimeric transcription factor HIF.

Figure 6.2: Control of HIF by PHD-mediated hydroxylation of HIF- $\alpha$.

Figure 6.3: Hydroxylated HIF- $\alpha$ is recognized by the vHL protein.

Figure 6.4: A schematic of the HIF hydroxylase reaction mechanism.

Figure 6.5: A simplified scheme of the ubiquitin-proteasome pathway.

Figure 6.6: The pathway for the stero-dependent proteolytic release of the active form of SREBPs from membranes.

Figure 6.7: The structure of SREBP genes and precursor proteins

Figure 6.8: The mechanism of HIF upregulation SREBP1.

Figure 6.9: Model for regulation of Sre1 by oxygen through oxygen-regulated binding between Ofd1 and Nro1.

Figure 6.10: Domain structure of OGFOD1 homologues from a variety of species.

Figure 7.1: Human embryonic kidney (HEK293) cells at high density.

Figure 8.1: Multiple alignments of OGFOD1 amino acid sequences from organisms.

Figure 8.2: Domain structure of OGFOD1 homologues from a variety of species.

Figure 8.3: Effect of hypoxia on OGFOD1 protein expression in HEK293A cells.

Figure 8.4: Quantitative real-time RT-PCR analysis of OGFOD1 gene expression in HEK293A cells.

Figure 8.5: Diagnostic restriction enzyme digestion.

Figure 8.6: Cell viability with the addition of increasing amounts of cycloheximide.

Figure 8.7: Effect of hypoxia on OGFOD1 protein degradation in HEK293A cells. 
Figure 8.8: Western blot of transiently transfected wildtype and mutant (P370A) of N-terminally FLAG-tagged human OGFOD1 overexpressed in HEK293A cells with 24 and 48 hours of hypoxia treatment.

Figure 8.9: Protein expression level of SREBP1 was measured from HEK 293A cells after transfection with wildtype (WT) and site-directed mutants (P370A) (MUT) of OGFOD1 under 24 or 48 hours of normoxia or hypoxia

Figure 8.10: The expression of SREBP1 protein from HEK293A cells after transfection with wildtype (WT) and site-directed mutant (P370A) (MUT) of OGFOD1 under hypoxic mimetic for 48 hours.

Figure 8.11: Western blot of proteins from cells overexpressing FLAG-OGFOD1 and immunoprecipitated using anti-FLAG agarose beads.

Figure 8.12: Silver-stained 8\% SDS-PAGE of proteins immunoprecipitating with FLAG-tagged mature OGFOD1 overexpressed in HEK293A cells.

Figure 9.1: Amino acid sequence of Nro1 from S.pombe and S.cerevisiae. 


\section{LIST OF ABBREVIATIONS}

ARNT: Aryl Hydrocarbon Nuclear Receptor Translocator

ATP: Adenosine-Triphosphate

bHLH: basic Helix-Loop-Helix

BSA: Bovine Serum Albumin

CBP: CREB-Binding Protein

CBZ: Proteasome inhibitor (Cbz-Leu-Leu-Leu-al)

CHX: Cycloheximide

DMEM: Dulbecco's Modified Eagle Medium

DMOG: Dimethyloxaloylglycine

DMSO: Dimethyl Sulfoxide

dsRNA: Double Stranded RNA

EDTA: Ethylenediaminetetraacetic Acid

ER: Endoplasmic Reticulum

FIH: Factor Inhibiting HIF

HEK: Human Embryonic Kidney

HEPES: 4-(2-Hydroxyethyl)-1-Piperazineethanesulfonic Acid

HIF: Hypoxia Inducible Factor

HRE: Hypoxic Response Element

HRP: Horse Radish Peroxidase

HS: Horse Serum

MTT: 3-(4,5-Dimethylthiazol-2-yl)-2,5-Diphenyltetrazolium Bromide 
OGFOD1: 2-Oxoglutarate and Iron-Dependent Oxygenase Domain Containing-1

ODD: Oxygen-Dependent Degradation Domain

PAS: Period/ARNT/Similar

PBS: Phosphate Buffered Saline

PDB: Protein Data Bank

Pfu: Pseudomonas fluorescens

PHD: Prolyl Hydroxylase

PI: Proteasome Inhibitor

PMSF: Phenylmethylsulfonyl Fluoride

P/S/A: Penicillin/Streptomycin/Amphotercin

PVDF: Polyvinylidene Fluoride

RT-PCR: Reverse Transcriptase-Polymerase Chain Reaction

SDS-PAGE: Sodium Dodecyl Sulphate Polyacrylamide Gel Electrophoresis

SREBP1: Sterol Regulatory Element Binding Protein

TAD: Transactivation Domain

TBST: Tris-Buffered Saline Tween-20

TEMED: Tetramethylethylenediamine

Ub: Ubiquitin

VEGF: Vascular Endothelial Growth Factor

vHL: von Hippel Lindau 


\section{INTRODUCTION}

\subsection{Hypoxia}

Approximately 2.5 billion years ago, oxygen $\left(\mathrm{O}_{2}\right)$ was introduced into Earth's atmosphere and life had the option of aerobic existence (Semenza, 2007). All the aerobic eukaryotic organisms contain mitochondria, subcellular organelles in which glucose is oxidized to carbon dioxide and water, thus completing the energy cycle (Semenza, 2007). In mitochondrial, $\mathrm{O}_{2}$ is an important substrate for energy production (Semenza, 2007). $\mathrm{O}_{2}$ reacts with the electrons transferred through the mitochondrial respiratory chain to produce $\mathrm{H}_{2} \mathrm{O}$, and this process is catalyzed by cytochrome c oxidase (complex IV) (Semenza, 2007). Normal atmospheric oxygen $(21 \%)$ is called normoxia; higher or lower than this oxygen level is defines as hyperoxia and hypoxia respectively. Anoxia is defined as the complete lack of oxygen.

Hypoxia occurs when there is an imbalance between tissue oxygen supply and consumption (Nangaku, 2006). Humans encounter low oxygen under physiological conditions such as high altitude and during in utero development. Humans also encounter low oxygen under pathophysiological conditions such as ischemic diseases. Hypoxia occurs during a) the cessation of blood flow to a tissue or organ (ischemia), b) a defect in the oxygen-carrying capacity of the blood or c) respiratory defects. Hypoxic diseases include cardiac arrest, stroke, anemia, sleep apnea and pulmonary diseases. Humans adapt to low oxygen by a) attempting to increase blood flow, and thus oxygen carrying capacity, to tissues and b) switching from aerobic to anaerobic pathways of metabolism. Thus, many of the genes that are induced by low oxygen include erythropoietin (induces erythrocyte maturation), vascular endothelial growth factor (induces 
angiogenesis), nitric oxide synthase (induces vasodilatation through nitric oxide), heme oxygenase-1 (heme turnover) and transferrin and transferrin receptor (iron transport) (Wenger, 2002). Adaptation to low oxygen is effected through transcription controlled by oxygendependent modification of protein function. Various transcription factors respond to hypoxia by initiating gene expression. Of these, the primary factor which controls most hypoxia-inducible gene expression is known as Hypoxia-Inducible Factor (HIF), which binds to a conserved sequence (the Hypoxia Response Element or HREs) in the promoter and enhancer regions of hypoxia-regulated genes.

\subsection{Hypoxia-Inducible Factors (HIFs)}

HIF is the most important transcription factor that mediates the cellular response to physiological decreases in oxygen tension (Figure 6.1). Three isoforms of this factor have been identified (HIF- 1, HIF-2, and HIF-3) (Safran and Kaelin, 2003). These proteins are heterodimers that are composed of an $\alpha$ subunit and a $\beta$ subunit. There are three isoforms of the $\alpha$ subunit (HIF- $1 \alpha$, HIF- $2 \alpha$ and HIF-3 $\alpha$ ) and three isoforms of the $\beta$ subunit (HIF-1 $\beta$, HIF-2 $\beta$ and HIF-3 $\beta$ ), the latter being a constitutively expressed aryl hydrocarbon receptor nuclear translocator (ARNT) (Wang et al, 1995). HIF belongs to the PER-ARNT-SIM (PAS) subfamily of the basic-helixloop-helix (bHLH) family of transcription factors. The name of PER-ARNT-SIM domain is derived from PERiod circadian protein/Ah Receptor Nuclear Translocator protein/SIngleMinded protein. In higher organisms, the PAS domain is a protein-protein interaction domain of signalling proteins (Ponting \& Aravind, 1997) whereas in lower organisms, it acts as a direct sensor to monitor the changes in light, redox-potential, oxygen and overall energy level of the 
cell (Taylor and Zhulin, 1999). The basic-helix-loop-helix (bHLH) is a protein structural motif that characterizes a family of transcription factors (Murre et al, 1994). The motif is characterized by two $\alpha$-helices linked by a loop and the helix-loop-helix portion is involved in dimerization. Overall, transcription factors containing this motif are dimeric, and the portion containing basic amino acid residues aids in DNA binding. Proteins containing bHLH domains typically bind to a consensus sequence (CANNTG), termed an E-box. (Chaudhary \& Skinner, 1999). HIF alpha and beta subunits are similar in structure as they both contain bHLH domains for DNA binding, PAS domains which facilitate heterodimerization and C-terminal transactivation domains (CAD) which recruit transcription coregulator proteins. Outside of these common domains, the two subunits differ considerably. HIF- $\alpha$ contains an oxygen-dependent degradation domain (ODDD). The ODDD contains two conserved oxygen regulatory sequences (LXXLAP, where L is leucine, $\mathrm{X}$ is any amino acid, $\mathrm{A}$ is alanine, and $\mathrm{P}$ is proline) in which the proline residues are hydroxylated when oxygen is present by oxygen-dependent enzymes known as prolyl hydroxylases. Another difference is that HIF- $\alpha$ contains two transcriptional activation domains (TAD): one is located at the C-terminus (CAD) of HIF- $\alpha$ and the other towards the N-terminus (NAD), within the ODDD (Chun et al., 2002). However, HIF- $\beta$ contains only a TAD at the Cterminus which does not appear to be necessary for transcriptional activation of hypoxiainducible genes (Huang et al., 1998). The third difference is that the HIF- $\alpha$ contains two PEST domains, which are not found in HIF- $\beta$; a peptide sequence which is rich in proline (P), glutamic acid $(E)$, serine $(S)$, and threonine $(T)$. This sequence is associated with proteins that have a short intracellular half-life (Rogers, et al., 1986). It acts as a signal peptide for protein degradation via 
Figure 6.1: The structure of the heterodimeric transcription factor HIF. HIF is composed of one of three alpha subunits (HIF-1 $\alpha$, HIF- $2 \alpha$ and HIF- $3 \alpha$ ) and one of three $\beta$ subunits (HIF-1 $\beta$, HIF-2 $\beta$, HIF-3 $\beta$ ). Both subunits contain a DNA-binding (basic) domain and a dimerization domain composed of helix-loop-helix and PAS (Period/ARNT/Single-minded) domains. HIF- $\alpha$ contains $\mathrm{N}$ - (NAD) and C-terminal (CAD) transactivation domains while HIF- $\beta$ contains only a CAD. The oxygen dependent degradation domain (ODDD) containing the two LXXLAP sequences of HIF- $\alpha$ is shown (Willmore, 2004). 


\section{HIF-1 is a Heterodimeric Helix-Loop-Helix PAS Protein}

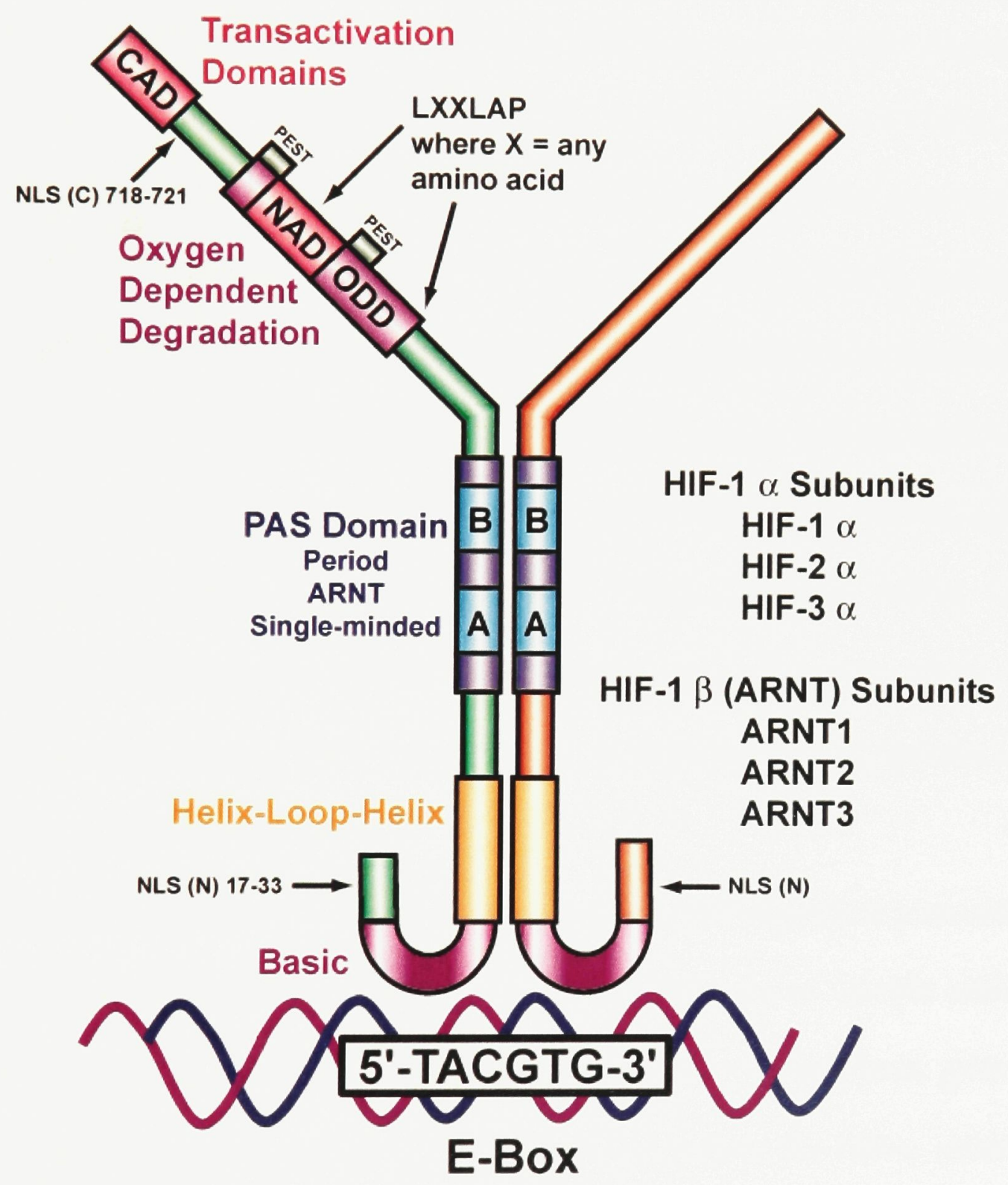


the proteosome or calpain (Reverte, et al., 2001; Shumway et al., 1999). The fourth difference is that the HIF- $\alpha$ contains two Nuclear Localization Signals (NLS) which mediate its translocation to the nucleus. HIF directly regulates over sixty genes (Semenza, 2003). Examples of HIF target genes include erythropoietin, vascular endothelial growth factor and glucose transporter-1.

Adaptation to low oxygen involves the expression of genes involved in angiogenesis, glucose and energy metabolism and cell proliferation. The basic region of HIF targets to a ciscore DNA recognition sequence (5'-NACGTG-3' where N can be G (41\%), T (36\%), C (15\%) or $\mathrm{A}(8 \%))$ known as the HRE, which is present in the enhancer regions of the promoters of most hypoxia-inducible genes (Safran and Kaelin, 2003; Lee et al. 2006). HIF- $\beta$ stability is not regulated by oxygen and it is constitutively expressed in cells under both normoxic and hypoxic conditions (Huang et al., 1998). HIF- $\beta$ dimerizes with many partner proteins involved in the response to toxins and other extracellular signals. However, HIF- $\alpha$ is very unstable, with a halflife of only 5 minutes under normoxic conditions. Under normoxia, HIF- $\alpha$ is rapidly hydroxylated, ubiquitinated and degraded by the proteasome (Bergeron et al., 1999). With the removal of oxygen under hypoxic conditions, HIF- $\alpha$ is stabilized and transcriptional activation of HIF target genes is therefore activated.

When oxygen is present, HIF- $\alpha$ undergoes a rapid, oxygen-dependent post-translational modification known as hydroxylation (the addition of an $\mathrm{OH}$ group to specific amino acids) (Figure 6.2). Hydroxylation is catalyzed by enzymes known as hydroxylases, which utilize molecular $\mathrm{O}_{2}$ to hydroxylate two prolines (Pro-402 and Pro-564) of the HIF- $\alpha$ subunit. Once hydroxylated, $\alpha$ subunit of HIF can be recognized and bound by the von Hippel Lindau (vHL) tumor suppressor protein. vHL is the substrate recognition subunit of a much larger complex of proteins known as the E3 ubiquitin ligase; which is composed of other proteins including CUL2, 
Rbx1 and Elongins B and C (Figure 6.3). With the assistance of the ubiquitin activating (E1) and conjugating (E2) enzymes, this ubiquitin ligase links ubiquitin onto HIF- $\alpha$ in long chain (Chun et al., 2002). Once ubiquitinated, HIF- $\alpha$ is targeted for proteolytic destruction by the $26 \mathrm{~S}$ proteasome. In the absence of oxygen, HIF- $\alpha$ cannot be hydroxylated, and consequently its ubiquitination and proteasomal degradation cannot occur. Therefore, HIF- $\alpha$ will accumulated in the cytoplasm, translocate to the nucleus and dimerize with HIF- $\beta$. The HIF heterodimer will then bind to HREs that are contained in the upstream regions of all genes induced by hypoxia and transactivate the basal transcription machinery (including RNA polymerase II and associated factors) through the transcriptional co-activators CBP (CREB-binding protein) or p300 (300 kDa protein) to increase the rate of transcription of downstream genes. CBP and p300 act as a bridging protein between HIF and the basal transcription machinery (Safran and Kaelin, 2003).

\subsection{Prolyl hydroxylases}

There are two families of hydroxylases, monoxygenases and dioxygenases, which consume molecular oxygen to hydroxylate target amino acids of proteins. Hydroxylation may not only alter a target protein's structure and function, but may also assist other posttranslational modifications of the protein, such as ubiquitination (indirect) or phosphorylation (direct). Both monoxygenases and dioxygenases utilize one and two atoms of dimolecular oxygen as their substrates respectively. The monoxygenases and dioxygenases utilize tetrahydrobiopterin and 2oxoglutarate as cofactors respectively according to the equations: 


\section{Monoxygenases:}

Amino acid + tetrahydrobiopterin $+\mathrm{O}_{2} \leftrightarrow$ hydroxyl-amino acid + hydroxyl-tetrahydrobiopterin

\section{Dioxygenases:}

Amino acid + 2-oxoglutarate $+\mathrm{O}_{2} \leftrightarrow$ hydroxyl-amino acid + succinate $+\mathrm{CO}_{2}$

Between the two families of hydroxylases, the dioxygenases are the most significant in terms of controlling protein function. The dioxygenases play an important role in cellular signalling, as transcription factors are targets of modification by these enzymes. Since the prolyl hydroxylase activity is absolutely dependent on oxygen, these dioxygenases play an important role as the cellular "oxygen sensor" and control of gene expression in response to changes in oxygen concentration in the cellular environment. This makes these enzymes very relevant to cellular and tissue responses to hypoxia-related diseases.

Hydroxylases are enzymes that can hydroxylate specific amino acids. The reaction of hydroxylation is shown in Figure 6.4. The dioxygenase enzymes include that proline 3-, 4- and 3,4-dioxygenases, lysine 5-dioxygenase, and aspartate/asparagine 3-dioxygenases. The prolyl hydroxylase domain (PHD) containing proteins (PHD1/HPH3, PHD2/HPH2 and PHD3/HPH1) belong to the proline hydroxylase family of enzymes and employ molecular oxygen, ascorbic acid, $\mathrm{Fe}^{2+}$ and 2-oxoglutarate as substrates to hydroxylate prolines of the target protein. HIF- $\alpha$ is also hydroxylated on a specific asparagine within its CAD. Factor inhibiting HIF-1 (FIH-1), like the PHD family members, is a $\mathrm{Fe}^{2+}$ - and 2-oxoglutarate-dependent dioxygenase. The interaction between HIF and CBP/p300 has been shown to also depend on asparagine hydroxylation of HIF- 
$\alpha$. Only when oxygen is absent, and the CAD of HIF- $\alpha$ is not hydroxylated, can the CAD of HIF- $\alpha$ interact with coactivators CBP/p300. However, under normoxia, FIH1 hydroxylates a conserved asparagine residue of the CAD, leading to an inhibition that prevents the interaction of the HIF- $\alpha$ CAD with CBP/p300 (Safran and Kaelin, 2003).

Hypoxic mimetics can inhibit the PHD hydroxylases and stabilize HIF- $\alpha$ under normoxic conditions. There are two kinds of inhibitors of hydroxylases: selective and non-selective. The cosubstrate 2-oxoglutarate, with $\mathrm{Fe}^{2+}$ ion binding to the catalytic domain, is critical for enzymatic PHD and FIH activity. Therefore, 2-oxoglutarate analogs such as $N$-oxalylglycine or its precursor dimethyloxalylglycine are selective inhibitors, which block access of the cosubstrate to the active site of the hydroxylase. Other compounds (such as desferrioxamine) chelate $\mathrm{Fe}^{2+}$, leading to interference with the catalytic activity of PHDs and FIHs. Due to the structural differences between PHDs and FIH, the 2-oxoglutarate analogue N-oxalyl-dphenylalanine, desferrioxamine and a few other inhibitors exhibit greater selectivity towards inhibiting FIHs than PHDs (Koivunen et al., 2004). This is because the active site of PHDs is sterically narrower than FIHs; those compounds have a more restricted access to the active sites of PHDs than FIHs (McDonough, 2006). Metal ions such as $\mathrm{Co}^{2+}, \mathrm{Cu}^{2+}, \mathrm{Zn}^{2+}$ and $\mathrm{Mn}^{2+}$ are nonselective inhibitors, which substitute for $\mathrm{Fe}^{2+}$ in the active sites of $\mathrm{Fe}^{2+}$-requiring enzymes (Schofield \& Ratcliffe, 2004).

Since ubiquitinated HIF- $\alpha$ passes through the ubiquitin-proteasome degradation pathway, inhibiting the activity of the proteasome will lead to the accumulation of HIF- $\alpha$. Proteasomemediated proteolysis is to selectively remove toxic and unneeded (often damaged) proteins within the cell (Adam, 2003). The 26S proteasome, which is approximately 2,000 $\mathrm{kDa}$ in molecular weight, contains one 20S core proteolytic complex and two 19S regulatory caps and is 
present in both the cytoplasm and the nucleus of all eukaryotic cells (Adam, 2003). The two 19S regulatory subunits, which attach to each end of the $20 \mathrm{~S}$ core particle, contain multiple ATPase active sites and ubiquitin binding sites (Adam, 2003). The 20S core is hollow and provides an enclosed cavity to allow for degradation of target proteins; the $19 \mathrm{~S}$ subunits recognize polyubiquitinated protein chains and transfer the attached target proteins to the catalytic core for degradation. Once recognized by the $19 \mathrm{~S}$ subunits, the long ubiquitin chain is removed, the ubiquitin is recycled and the denatured target protein is directed into the center of the $20 \mathrm{~S}$ complex (Adam, 2003) (Figure 6.5).

Inhibitors of the proteasome would not prevent the hydroxylation or the ubiquitination of HIF- $\alpha$, but would prevent its subsequent degradation. Inhibitors such as the peptide aldehyde inhibitor MG132 (Cbz-Leu-Leu-Leu-al) forms a transition state hemiacetyl complex with the threonine active site of the proteasome which interferes with its ability to degrade proteins (Chun et al., 2004). MG132 was used in the present study as a proteasome inhibitor. 
Figure 6.2: Control of HIF by PHD-mediated hydroxylation of HIF-a (Willmore, 2004). When oxygen is present, HIF- $\alpha$ is hydroxylated on two prolines by PHD hydroxylases. This promotes its recognition by vHL, complexed with the E3 ubiquitin ligase, ubiquitination and subsequent degradation by the proteasome. When oxygen is absent, HIF- $\alpha$ is not hydroxylated, ubiquitinated or degraded, moving to the nucleus where it dimerizes with HIF- $\beta$ and promotes transcription through HREs. HIF does so through a bridging protein (CBP or p300) that binds to HIF transactivation domains and interacts with the basal transcription machinery (Willmore, 2004). 


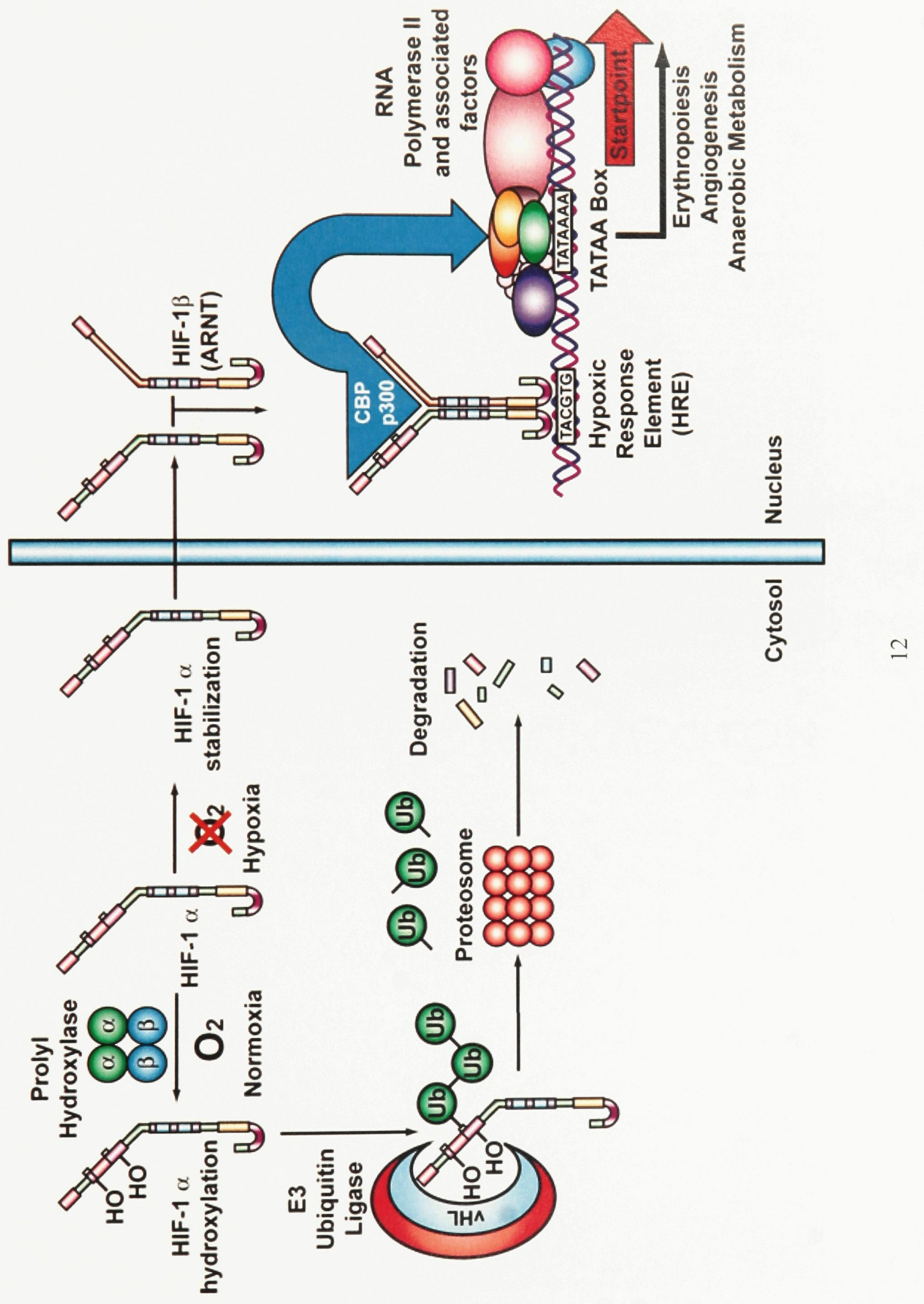


Figure 6.3: Hydroxylated HIF- $\alpha$ is recognized by the vHL protein, the substrate recognition subunit of the E3 ubiquitin ligase which is composed of Cul-2, Elongins B and C, Rbx-1 and vHL. Hydroxylated HIF- $\alpha$ is polyubiquitinated by the E1, E2 and E3 ubiquitination enzymes and is targeted for proteolytic degradation by the proteosome (Willmore, 2004). 


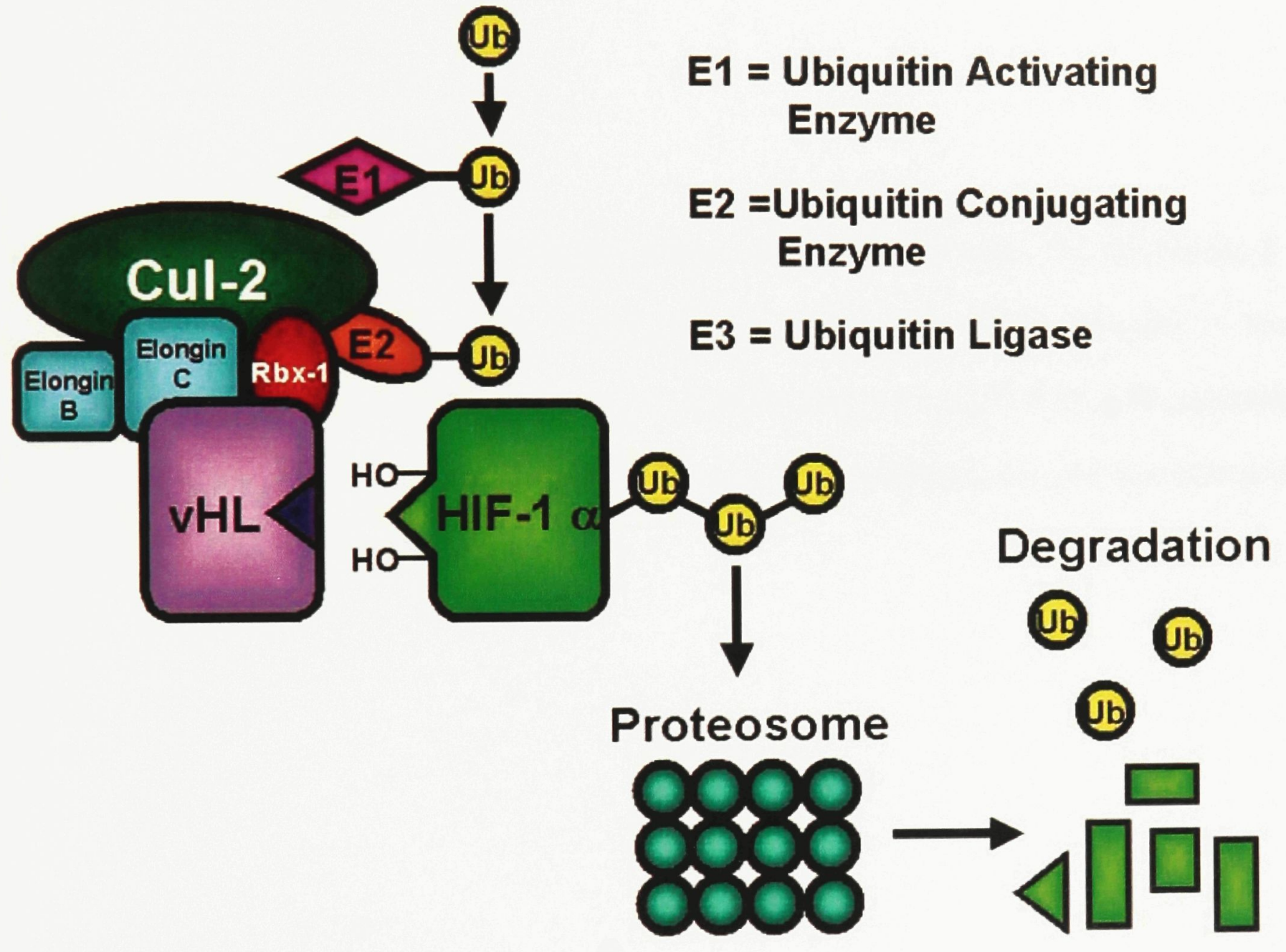


Figure 6.4: A schematic of the HIF hydroxylase reaction mechanism. The cosubstrate 2oxoglutarate coordinates the binding of the $\mathrm{Fe}^{2+}$ ion within the catalytic domain of the hydroxylase. Molecular dioxygen then enters the active site and one oxygen atom is incorporated into the hydroxylated HIF residue and the other oxidizes 2-oxoglutarate, forming succinate and $\mathrm{CO}_{2}$ (Masson and Ratcliffe, 2003). 


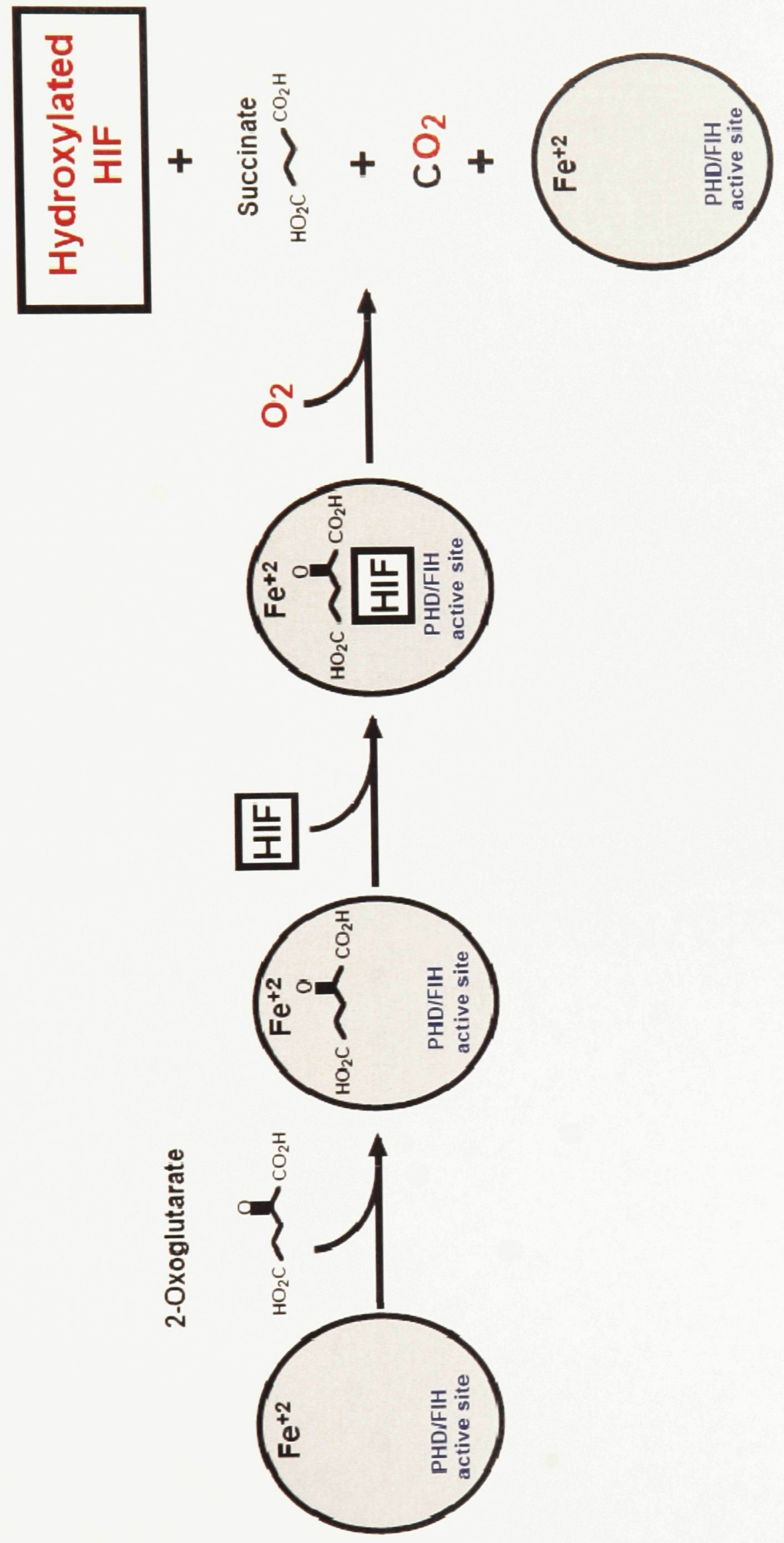


Figure 6.5: A simplified scheme of the ubiquitin-proteasome pathway. Once a series of ubiquitin molecules are attached to the substrate protein, the $26 \mathrm{~S}$ proteasome remove the ubiquitins and degrades the tagged protein in an ATP-dependent manner (Adam, 2003) 


\section{THE UBIQUITIN - PROTEASOME PATHWAY}

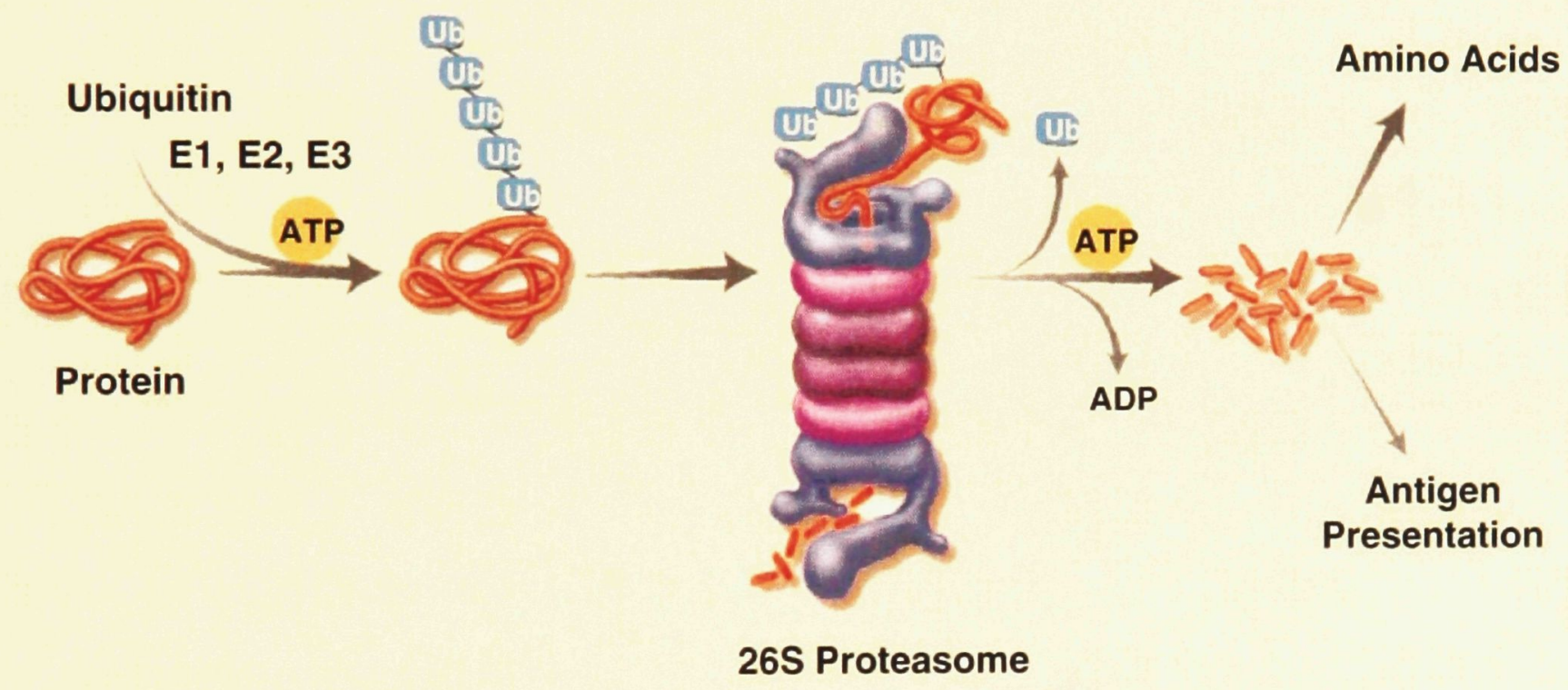




\subsection{Sterol regulatory element binding protein-1 (SREBP1)}

SREBPs belong to the basic helix-loop-helix-leucine zipper (bHLH-Zip) family of transcription factors. They are synthesized as inactive precursors bound to the endoplasmic reticulum (ER) and are proteolytically processed to the mature (functional) form of the protein (Brown \& Goldstein, 1997). Each SREBP precursor, of about 1,150 amino acids, is composed of three domains: (a) an N-terminal domain of about 480 amino acids that contains the bHLH-Zip region for DNA binding; (b) two hydrophobic transmembrane-spanning segments connected by a short loop of about 30 amino acids that inserts into the lumen of the ER; and (c) a C-terminal domain of about 590 amino acids with an essential regulatory function (Jay et al., 2002). The Nterminal domain of each SREBP is released as the active/mature form by the protease from membrane, which travels to the nucleus and act as a transcription factor (Brown \& Goldstein, 1997). There are three proteins involved in SREBP processing: SREBP cleavage-activating protein (SCAP); Site-1 protease (S1P) and Site-2 protease (S2P). Newly synthesized SREBP is localized on the ER membrane, where its C-terminal regulatory domain associates with the Cterminal domain of SCAP. SCAP is a sterol-sensor; the N-terminal domain of SCAP having eight transmembrane helices which include the sterol-sensing domain (Sato, 2008). The Cterminal domain of SCAP contains five WD repeats, which are sequences of approximately 40 amino acids found in many proteins and terminating in a tryptophan-aspartic acid (W-D) dipeptide and function in protein-protein interactions (Neer et al., 1994). The WD repeat domain is the region of SCAP that forms a complex with the C-terminal domain of SREBPs (Sato, 2008). When cells become short in cholesterol, SCAP bind to and transfers SREBP from the ER to the Golgi apparatus (Figure 6.6). In the Golgi apparatus, S1P, a membrane-bound serine protease, 
cuts SREBP at its luminal loop, between the two membrane-spanning segments, dividing SREBP in half (Horton et al., 2002). A second protease, S2P, a membrane-bound zinc metalloproteinase, cleaves the N-terminal bHLH-Zip domain, releasing it from the membrane to the cytoplasm. The final (mature) form of SREBP is designated the N-terminal SREBP (SREBP1N). In the cytoplasm SREBP1N interacts with importin- $\beta$, which is a nuclear escort protein, which guides SREBP1N into the nucleus (Sato, 2008). In the nucleus, SREBP1N dimerizes via its leucine zipper and binds to sterol response elements (SREs) in the promoter/enhancer regions of multiple target genes to activate their transcription (Horton et al., 2002).

When the cholesterol concentration of cells rises, the sterol sensing domain of SCAP detects the excess cholesterol, and through a change in its conformation. Due to the conformation changed, SCAP is not able to bind to SREBP and transported from the ER to the Golgi apparatus. As a result, SREBP is not able to be cleaved by S1P and S2P in the Golgi apparatus, therefore their bHLH-Zip domains cannot be released from the ER membrane, and the transcription of target genes ceases (Goldstein et al., 2002).

The mammalian genome encodes three different SREBP proteins, SREBP-1a, SREBP-1c, and SREBP-2. The gene on human chromosome22q13 encodes SREBP-2 (Hua et al., 1995), a single gene on human chromosome 17q11.2 encodes both SREBP-1a and -1c through the use of alternative transcription start sites. Alternative splicing results in alternative forms of Exon 1 being incorporated into the gene, designated Exons 1a and 1c (Miserez et al., 1997). SREBP-1a is an effective activator of all SREBP-responsive genes, including those that mediate the synthesis of cholesterol, fatty acids, and triglycerides (Brown \& Goldstein, 1997). Exon 1a encodes a longer acidic transactivation segment than does Exon 1c, and thus Exon1a mediates high-level transcriptional activation (Figure 6.7) (Horton et al., 2002). SREBP-1c preferentially 
promotes fatty acid synthesis but not cholesterol synthesis (Brown \& Goldstein, 1997). Similar to SREBP-1a, SREBP-2 has a long N-terminal transactivation domain which preferentially enhances cholesterol synthesis. In most cultured cell lines, SREBP-1a and SREBP2 are the predominant isoforms of SREBP; however, in the liver and most other intact tissues, SREBP-1c and SREBP-2 are more prevalent (Shimomura et al., 1997).

\subsection{Protein modification of SREBPs regulates their activities}

The mature form of SREBP is a short-lived protein with a half-life of approximately 3 hours (Sato, 2008). In the nucleus, SREBPs are unstable and are rapidly degraded by the ubiquitin-26S proteasome pathway (Bengoechea-Alonso \& Ericsson, 2009). The rapid turnover of nuclear SREBPs does not correlate with intracellular sterol levels. Moreover, treatment with proteasome inhibitors causes the mature form of SREBPs become stable and enhances the transcription of their target genes (Sato, 2008). The phosphorylation of SREBPs is catalyzed by glycogen synthase kinase-3 beta (GSK-3) on the serine and/or threonine residues of SREBPs, near their sites of ubiquitination. Phorphorylation promotes the ubiquitination of SREBPs, the phosphorylation of amino acids adjacent to the site creates a docking site for Fbw7, which is a component in the E3 ubiquitin ligases which ubiquitinate SREBPs (Bengoechea-Alonso \& Ericsson, 2009). Polyubiquitination is the rate-limiting step in SREBPs degradation. The E3 ubiquitin ligase which catalyze the final reaction of SREBP ubiquitination is a complex comprised of Skp1, Cul1, Rbx1 and Fbw7, a family member of the F-box proteins (BengoecheaAlonso \& Ericsson, 2009). 
Figure 6.6: The pathway for the sterol-dependent proteolytic release of the active form of SREBPs from membranes. SCAP acts as a sensor of sterols and an escort of SREBPs. When the intracellular concentration of sterol decreases, SCAP binds to SREBPs and escorts them from the ER to the Golgi apparatus, where Site-1 protease (S1P) and Site-2 protease (S2P) sequentially cleave the SREBPs to release their N-terminal bHLH-Zip domain from the membrane. The bHLH-Zip domain forms a homodimer and interacts with importin- $\beta$ which escorts them to the nucleus. When the homodimer enters the nucleus, it binds to sterol response elements (SREs) present in the enhancer/promoter regions of target genes, activating their transcription. When cellular cholesterol increases, the SCAP/SREBP complex is no longer integrated into ER transport vesicles and SREBPs are not able to reach the Golgi apparatus. Thus, the bHLH-Zip domain cannot be proteolytically released from the membrane and, eventually, transcription of all SREBP1N target genes is declined (Sato, 2008). 
Endoplasmic reticulum
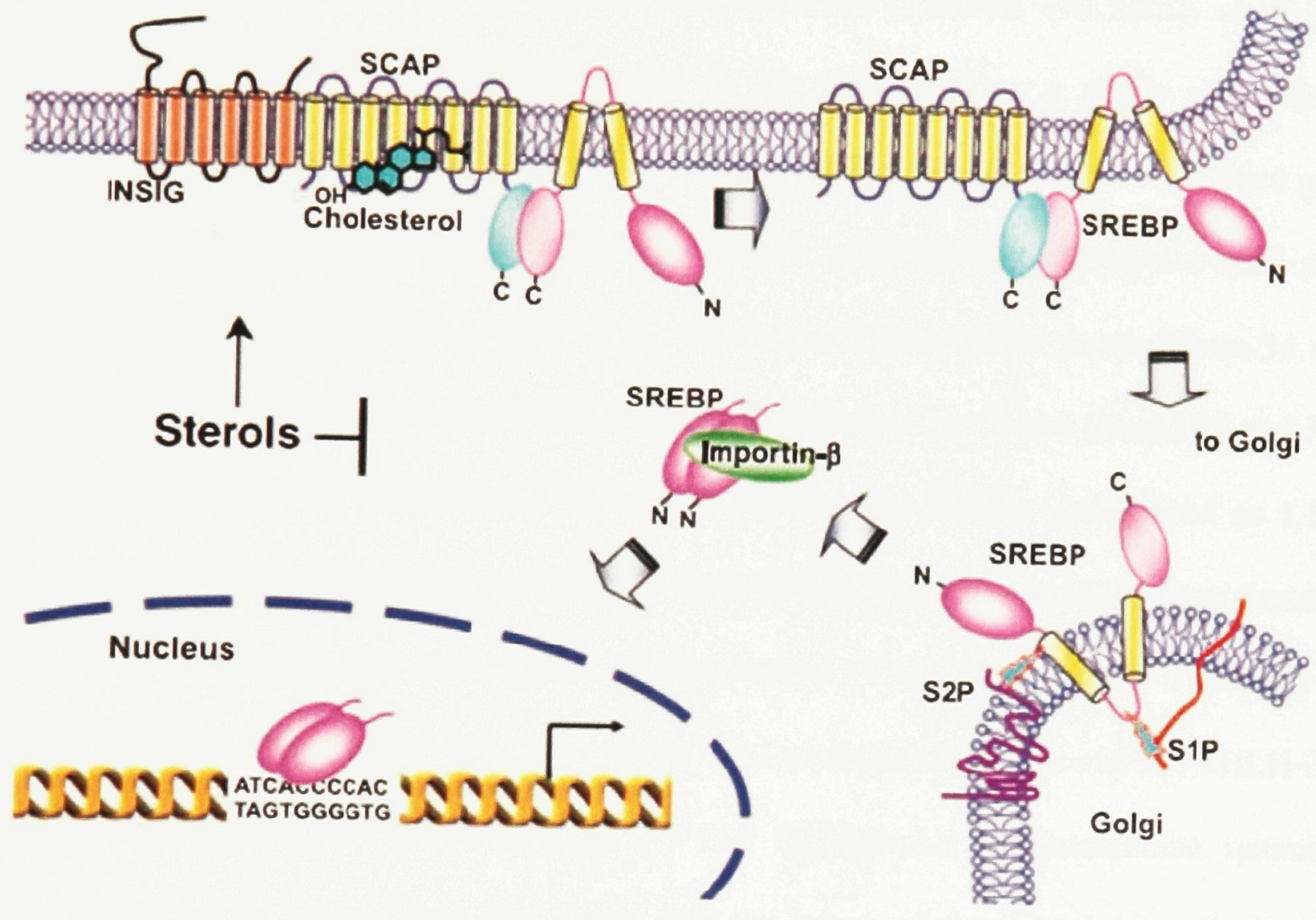
Figure 6.7: The structure of SREBP genes and precursor proteins. The family of SREBP proteins contain three isoforms: SREBP-1a and 1c are encoded from a single gene named SREBP-1 located on human chromosome 17p11.2 and SREBP-2 produced from a different gene named SREBP-2 located on human chromosome 22q13. Alternative transcription start sites produce two transcripts, SREBP-1a and -1c, in which two different first exons (Exon 1a and Exon 1c) are utilized. In humans, alternative splicing also occur in the $3^{\prime}$ end (Exons 18 and 19). The inactive precursors of SREBPs are bHLH-LZ transcription factors synthesized as 1,150 amino acid proteins bound to the ER membranes. Each SREBP precursor contains three domains: (a) an N-terminal domain that contains the transactivation (TA) domain (the TA domain of SREBP-1a is longer than that of $-1 \mathrm{c}$ ), (b) a serine- and proline-rich region and the bHLH-Zip domain for dimerization and DNA binding, (c) two hydrophobic transmembrane spanning segments connected by a short loop that inserts into the lumen of the ERand (d) a C-terminal segment regulatory domain (Eberle et al., 2004). 
SREBF-1 gene
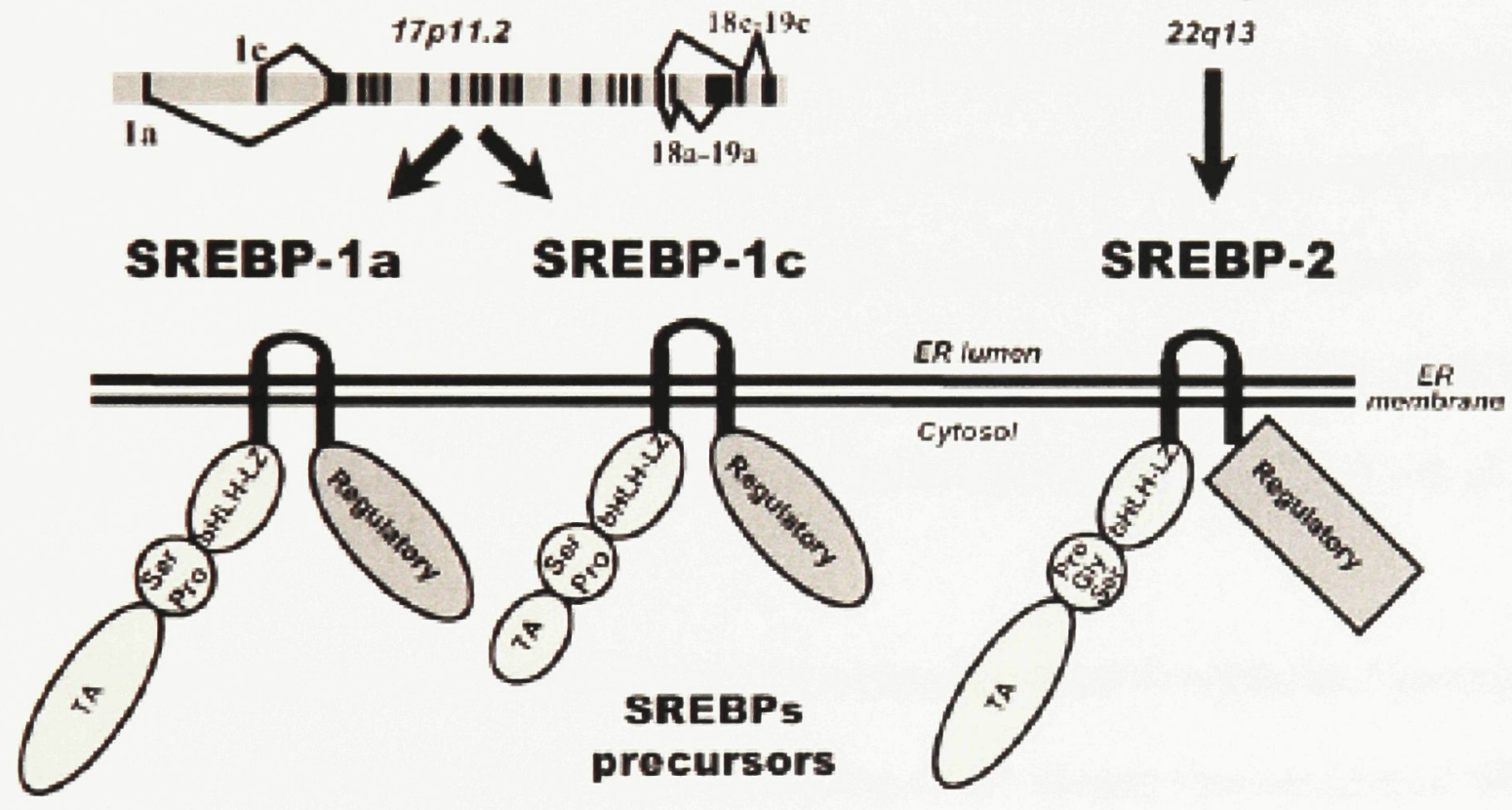

SREBF-2 gene

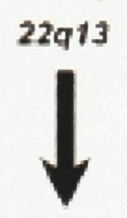

2913

$\downarrow$

SREBP-2 


\subsection{SREBP1 and hypoxia}

Sleep apnea is a hypoxia-related disease and is the periodic fail of the upper airway during sleep, causing periods of intermittent hypoxia (IH) (Li et al., 2006). Multiple metabolic disorders including insulin resistance, glucose intolerance, dyslipikemia and fatty liver disease are related to sleep apnea ( $\mathrm{Li}$ et al., 2006). IH causes an increase in liver triglycerides (TG) via the upregulation of SREBP. The mechanism by which IH upregulates SREBP-1 is not absolutely clear at present.

There are two possible mechanisms to explain how hypoxia could upregulate cellular triglycerides. The first may be that HIF does not affect SREBP-1 expression at the transcriptional level, but mediates SREBP-1 levels at the posttranscriptional level. The active form of SREBP1 is upregulated during hypoxia by HIF-induced SCAP expression (Li et al., 2006). The SCAP gene promoter contains a HRE (5'-ACGTG-3'). HIF enhances SREBP-1 activity via SCAP and consequently leads to an upregulation of cellular lipid biosynthesis during IH (Li et al., 2006) (Figure 6.8).

As Figure 6.8 shows, IH induction of HIF expression leads to enhanced transcription of SCAP. Increased SCAP results in increased processing of the nuclear (active) form of SREBP1. The upregulation of SREBP1 activity results in an increased biosynthesis of Stearoyl CoA desaturase (SCD)-1. SCD-1 could upregulate the production of monounsaturated fatty acids (MUFA) and, subsequently, the cellular level of triglycerides (Li et al., 2006).

The second possible mechanism is that, in contrast to the finding by $\mathrm{Li}$ et al (2006), hypoxia affects SREBP1 at the level of transcription. According to quantitative RT-PCR data from another group, the mRNA of SREBP-1 was significantly increased by treatment with 
hypoxia, suggesting that hypoxia-inducible factors are responsible for an increase in SREBP1 expression during hypoxia (Furuta et al., 2008).

\subsection{Sre1N and Ofd1 in yeast cells}

In fission yeast (Schizosaccharomyces pombe), sterol levels are regulated by ambient oxygen concentrations. Under hypoxia, sterol synthesis is inhibited and Sre1 is proteolytically cleaved, releasing the N-terminal transcription factor domain (Sre1N) (Lee et al., 2009). Sre1, the fission yeast sterol regulatory element binding protein and the orthologue of mammalian sterol regulatory element binding protein (SREBP), is an ER membrane-bound transcription factor (Hughes \& Espenshade, 2008). Sre1N responds to changes in oxygen-dependent sterol synthesis. In response to cellular hypoxia, Sre1 is proteolytically cleaved and the N-terminal transcription factor (Sre1N) is released to dimerize and activate gene expression essential for hypoxic growth. The mechanism of Srel is not mediated by the levels of sterols but by the oxygen concentration (Hughes \& Espenshade, 2008). Upon the return to normoxic conditions, Sre1N is degraded by the proteasome. Thus Sre1N accumulates only under hypoxic conditions. Ofd1 (the homologue of mammalian OGFOD1), an uncharacterized prolyl 4-hydroxylase-like 2oxoglutarate- $\mathrm{Fe}^{2+}$ dioxygenase, promotes the degradation of Sre1N under normoxic conditions (Hughes \& Espenshade, 2008). In yeast cells, Ofd1 contains two different functional domains to regulate Sre1N degradation; its N-terminal dioxygenase domain is an oxygen sensor, similar to the PHD hydroxylases that modify HIF- $\alpha$ and the C-terminal domain accelerates Sre $1 \mathrm{~N}$ turnover under normoxic conditions (Hughes \& Espenshade, 2008). Conversely, in the absence of oxygen, this acceleration is lost, leading to increased stability of Sre1N. In fission yeast cells, Ofd1 acts 
as both an oxygen sensor and an effector to mediate Sre1N levels in response to fluctuations in environmental oxygen (Hughes \& Espenshade, 2008). In S. pombe cells, Ofd1 increased under hypoxia, at both the mRNA and protein levels, and knockdown of Srel could abolish this induction (Hughes \& Espenshade, 2008).

A recent study has found that a novel protein associates with the C-terminal end of Ofd1, regulating its interaction with Sre1N. The Negative Regulator of Ofd1 (Nro1) binds to the Ofd1 C-terminal domain to inhibit the degradation of Sre1N under low oxygen conditions (Lee et al., 2009).

In $S$. pombe, under normoxic conditions, the N-terminal dioxygenase of Ofd1 may hydroxylate the C-terminal domain of Ofd1 and prevent the interaction of Nro1. This would allow the C-terminus of Ofd1 to accelerate the destabilization of Sre1N and its subsequent degradation. It is unclear whether this occurs through direct interaction between Sre1N and the C-terminus of Ofd1. Conversely, under hypoxic conditions, the N-terminal dioxygenase is unable to hydroxylate the C-terminus of Ofd1, leading to the association of the Nrol inhibitor with the C-terminus of Ofd1, and enhancing Sre1N stabilization, allowing for its transcriptional activation of Sre $1 \mathrm{~N}$ controlled genes. In this mechanism, the N-terminal domain dioxygenase of Ofd1 acts as an oxygen sensor to mediate the binding of the inhibitor Nro1 to the Ofd1 Cterminal domain, thereby controlling Sre1N stability (Lee et al., 2009). Nro1 is not a universal inhibitor for protein degradation (Takeda and Yanagida, 2005). The N-terminal dioxygenase domain of Ofd1 regulates the binding of Nro1 to the Ofd1 C-terminal domain with different oxygen concentrations, thereby modulating the stability of Sre $1 \mathrm{~N}$ in response to varying oxygen tensions (Figure 6.9) (Lee et al., 2009). It is currently unknown whether there is a third protein or small molecule which acts as the substrate of the N-terminal dioxygenase of Ofd1. 


\subsection{2-Oxoglutarate and iron-dependent oxygenase domain containing-1 (OGFOD1) in mammalian cells}

OGFOD1 (2-oxoglutarate and iron-dependent oxygenase domain containing-1) is a 542 amino acid protein that contains one PKHD (prolyl/lysyl hydroxylase domain) and is able to bind both ascorbate and iron as cofactors (Epsten et al., 2001). Alternative splicing events result in two isoforms of OGFOD1; isoform 1 and isoform 2. In the isoform 2, the first 140 amino acids are missing in comparison to isoform 1 . The gene that codes for the human OGFOD1 is on chromosome 16. Sequence analysis and alignments of the H. sapiens OGFOD1 homologues with the same protein in a wide range of eukaryotes from fungi to humans, indicated that OGFOD1 homologues are approximately 550 amino acids long and all contain the conserved LXXLAP sequence which is also present in HIF- $\alpha$.

\subsection{Hypothesis}

Some proteins may be degraded under normoxic conditions in a manner similar to that of HIF- $\alpha$. Upon exposing cells to hypoxia, proteins may be stabilized and thus enhance their function within the cell. These proteins may play a central role in oxygen-dependent pathways that are HIF-independent (i.e. not regulated by HIF-dependent gene expression) but are just as crucial to hypoxia survival of the cell (Abu-Farha, 2005). My hypothesis is that OGFOD1 may be regulated in an oxygen-dependent manner similar to that of HIF- $\alpha$ and may be stabilized under hypoxic conditions. This hypothesis comes from the recent study that, in fission yeast cells, 
Ofd1 mRNA and protein expression levels increased under low oxygen conditions (Hughes \& Espenshade, 2008).

This thesis examines OGFOD1 (Ofd1 homologue in mammals) gene and protein expression in response to hypoxia and hypoxic mimetics, as well as the rate of OGFOD1 protein turnover under normoxic and hypoxic conditions. OGFOD1 contains the conserved LXXLAP sequence which is found twice in HIF- $\alpha$. The LXXLAP sequence in OGFOD1 is phylogenetically conserved in a number of organisms, which makes it highly like that OGFOD1 may be controlled in an oxygen-dependent manner similar to HIF- $\alpha$.

The above hypothesis is to investigate the character of OGFOD1 affected by low oxygen; the following hypothesis is interesting in establishing the function of OGFOD1, which is the effect of OGFOD1 on SREBP1 under low oxygen condition.

In Saccharomyces cerevisiae, the budding yeast, Nro1 (YOR051C) binds to the Ofd1 homologue Tpa2 in an oxygen-dependent manner, as detected by global affinity-purification studies; similar to the mechanism that exists in S. pombe (Korgan et al, 2006). Since the Cterminal domain of Ofd1 shows significant identity to the C-terminal domain of OGFOD1, this suggests that a similar oxygen-dependent regulatory mechanism may exist in humans (Hughes and Espenshade, 2008). We predicted that human OGFOD1 may accelerate human SREBP1N degradation in the presence of oxygen, in a manner similar to the acceleration of degradation of Sre1N by Ofd1 in fission yeast. Since the Nro1 homologue in mammals has not yet been identified, we cloned, tagged and overexpressed human OGFOD1 in mammalian cells to undertake coimmunoprecipitation studies to determine protein-protein interactions with the mammalian protein. 
Figure 6.8: The mechanism of HIF upregulation SREBP1. Hypoxia induces HIF expression, which subsequently promotes the transcription of SCAP by binding to HREs present in the promoter/enhancer regions of SCAP. SCAP binds to SREBP-1 and transfer SREBP1 from ER to Golgi apparatus to be proteolytically processed the active form of SREBP1 (SREBP1N). The dimer of active SREBP1N enters to the nucleus to enhance target gene expression, such as SCD1. Consequently, SCD1 enhances cellular triglyceride biosynthesis (Li et al., 2006). 


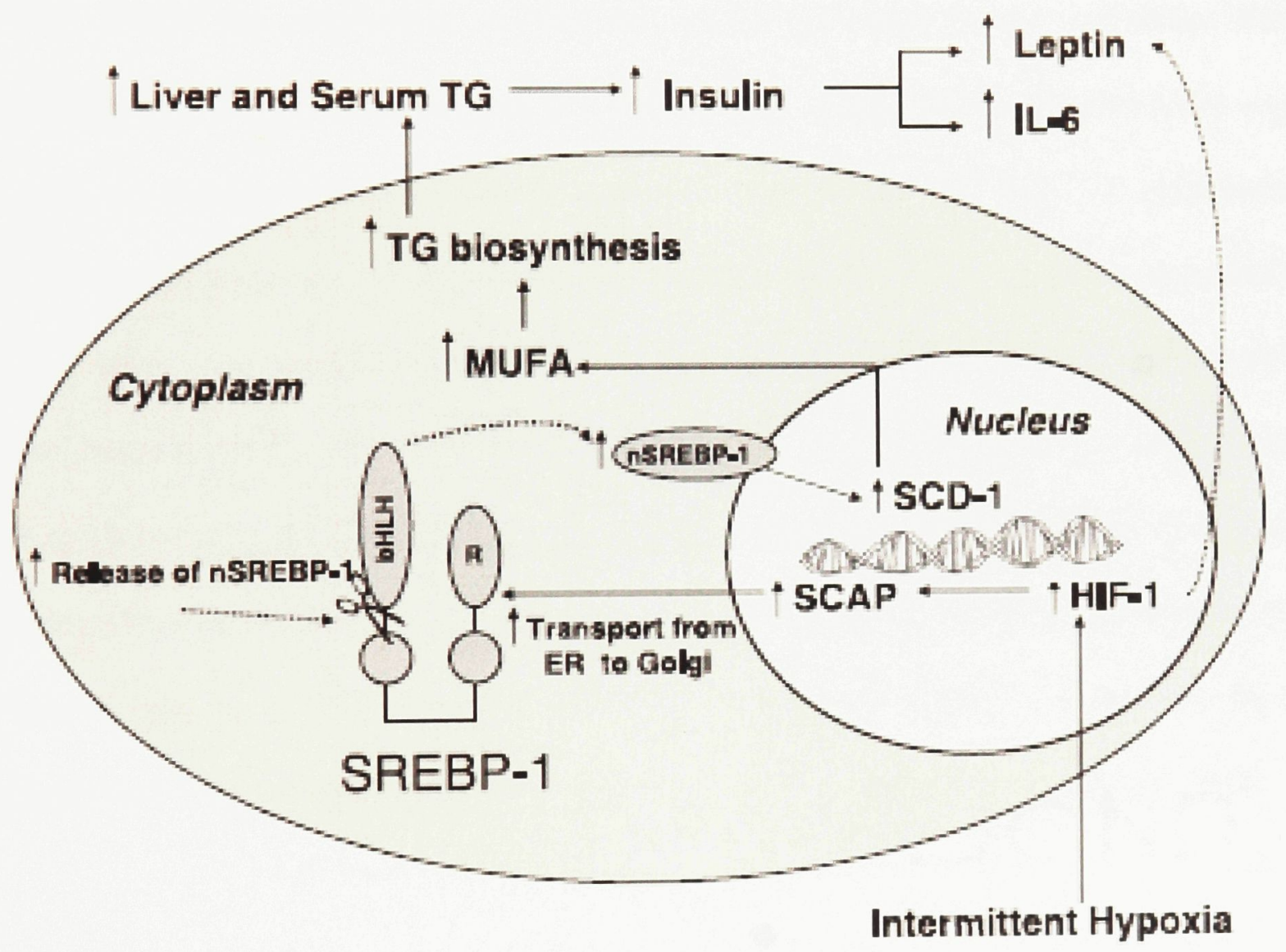




\section{Figure 6.9: Model for regulation of Sre1 by oxygen through oxygen-regulated binding}

between Ofd1 and Nro1. In fission yeast (S. pombe) cells, sterol levels are regulated by oxygen. Under hypoxia, oxygen-dependent sterol synthesis is inhibited and Sre1 is proteolytically cleaved, leading to increased Sre1N. Under normoxia, degradation of Sre1N is accelerated by Ofd1. Ofd1 senses the oxygen concentration to regulate the stability of Sre1N via Nro1. The interaction between Ofd1 and Nro1 is oxygen-dependent. In the presence of oxygen, the Nterminal regulatory domain (N-Reg) of Ofd1 detects oxygen and prevents Nrol to bind the Cterminal degradation domain (CTDD), leading to the acceleration of the degradation of Sre1N. Under low oxygen or hypoxic mimetics, the N-Reg is inactive, Nro1 is able to bind the Ofd1 CTDD, and Sre1N degradation is inhibited (Lee et al., 2009; Hughes \& Espenshade, 2008). 


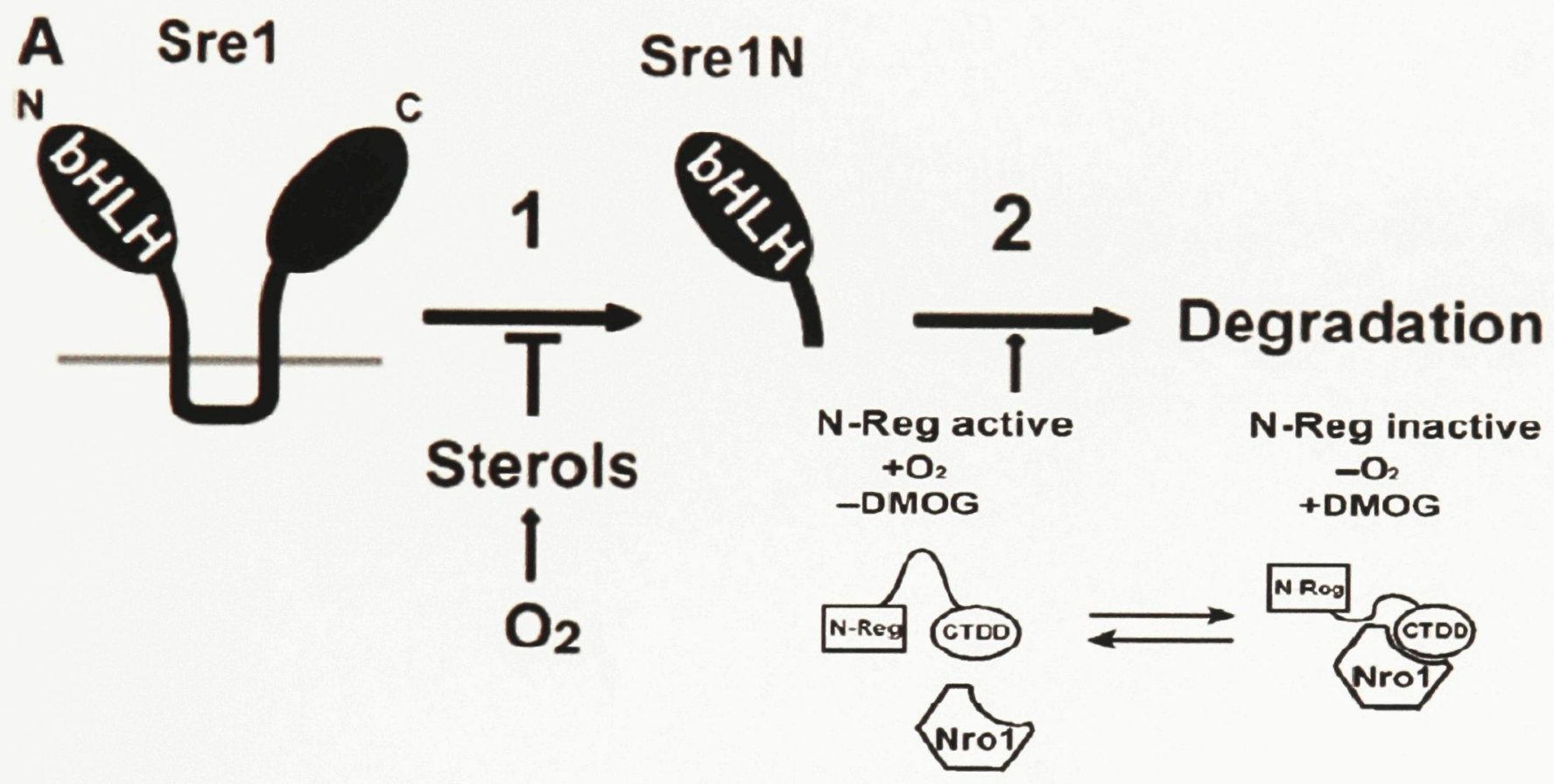


Figure 6.10: Domain structure of OGFOD1 homologues from a variety of species. The P4Hc domain (in black) is the same as the PKHD domain of the human protein (taken from Hughes and Espenshade, 2008). 


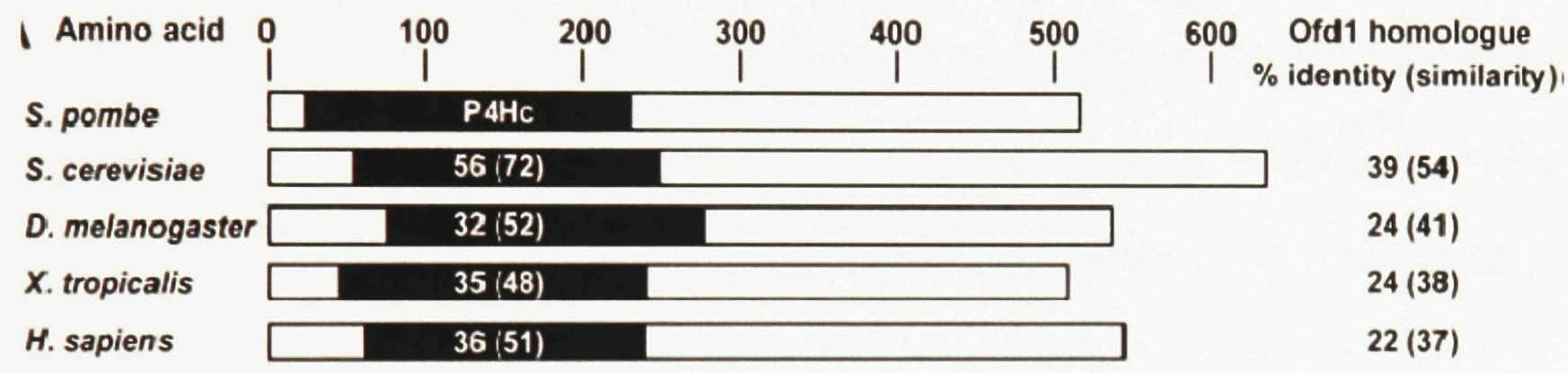




\section{Materials and Methods}

\subsection{Database search for the LXXLAP sequence}

A search of protein databases (SWISS-PROT and TrEMBL; Boeckmann et al., 2003) for proteins containing the LXXLAP sequence revealed over 5,000 different proteins, in various organisms, that contained the sequence and these were grouped by a PERL-based algorithm (Wall 1987-2001). The list of resulting proteins was further narrowed according to a) their identity, b) the number of species the protein emerged in and c) the potential involvement of the protein in oxygen-sensing pathways. 2-oxoglutarate- and iron-dependent oxygenase domain containing 1 (OGFOD1) was chosen from this protein list as a potential candidate for further testing. The fact that the OGFOD1 is a prolyl hydroxylase itself, with an additional length of protein involved in protein-protein interactions, made this an interesting candidate for further study. The LXXLAP sequence in OGFOD1 occurs in the C-terminal protein-protein interaction domain.

\subsection{Chemicals and cell culture}

All chemicals were purchased from Sigma (St. Louis, MO) unless otherwise specified. Human embryonic kidney cells (HEK293), containing sheared adenovirus 5 DNA, were first described in 1977 (Graham et al. 1977) (Figure 7.1). The number 293 refers to the cell clone number that was derived from 293rd experiment. HEK293 are adherent cells with two subtypes; 293A and 293T. The primary difference between $293 \mathrm{~T}$ and 293A is that $293 \mathrm{~T}$ contains an 
additional SV40 large T antigen which allow for episomal replication of transfected plasmids containing the SV40 origin of replication. In this study, 293A were used (Shaw et al, 2002). Cells were maintained in media containing $87 \%$ Dulbecco's Minimal Essential Medium (DMEM), $10 \%$ horse serum and $3 \%$ antibiotics (penicillin/streptomycin/antimycotic) (Invitrogen, Grand Island, NY). Cells were maintained in $75 \mathrm{~cm}^{2}$ flasks at density of $1 \mathrm{X} 10^{6}$ cells $/ \mathrm{mL}$ at $37^{\circ} \mathrm{C}$ and $5 \% \mathrm{CO}_{2}$ in a humidified tissue culture incubator (Thermo Forma, Marietta, $\mathrm{OH})$. Confluent cultures were washed in $1 \mathrm{X}$ phosphate buffered saline (PBS) (10 mM phosphate buffered saline, $138 \mathrm{mM} \mathrm{NaCl}, 2.7 \mathrm{mM} \mathrm{KCl}$, pH 7.4 and trypsinized every three days. Cells were counted using the trypan blue exclusion method (Altman et al., 1993) ahead of seeding cells for experiments. In general, $90 \mu \mathrm{L}$ of cells were mixed with $10 \mu \mathrm{L}$ of trypan blue (Sigma-Aldrich, St. Louis, MO) in an Eppendorf tube. After mixing well, cells were counted using a hemocytometer, and cell density was calculated by the equation:

Cell Density $($ cells $/ \mathrm{mL})=$ the number of cells on 10 large squares $(1 \mathrm{X} 1 \mathrm{X} 0.1$ millimeters each $)$ * dilution factor * $1000 \mu \mathrm{L} / \mathrm{mL}$

Cells treated under hypoxic conditions $\left(1 \% \mathrm{O}_{2}, 5 \% \mathrm{CO}_{2}, 37^{\circ} \mathrm{C}\right)$ were placed in a triplegas incubator (Thermo Forma, Marietta, $\mathrm{OH}$ ) for treatment. Hypoxic mimetic treatment included treatment of cells with cobalt (100 $\mu \mathrm{M}$ cobalt chloride), proteasome inhibitor (PI; 10 $\mu \mathrm{M}$ Cbz-Leu-Leu-Leu-al (MG132)) (Lee and Goldberg, 1998) or deferrioxamine (DFO) (100 $\mu \mathrm{M})$ and maintained under normoxic conditions. 
Figure 7.1: Human embryonic kidney (HEK293) cells at high density [ATCC; CRL-1573]. 


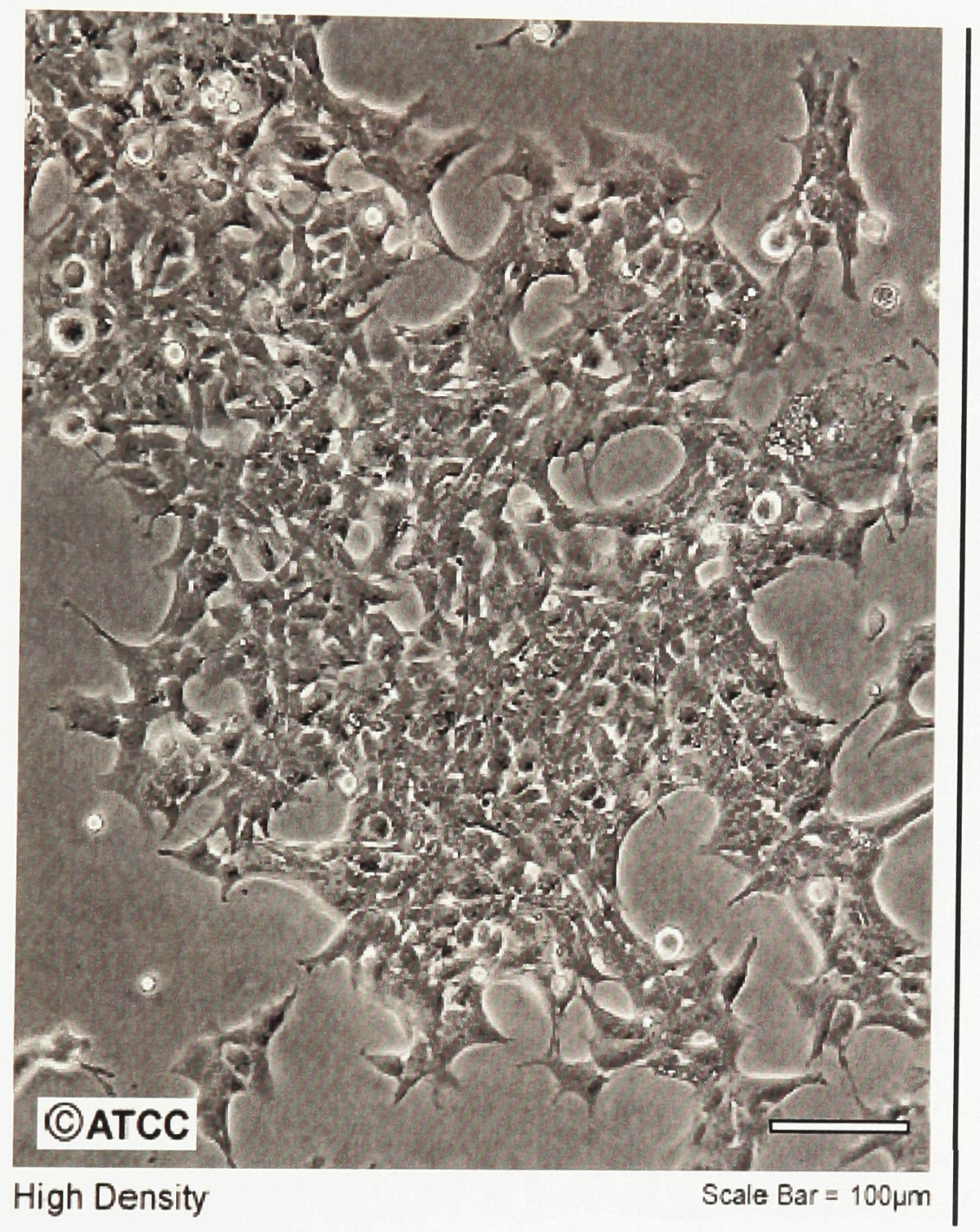




\subsection{MTT assay}

To measure the viability of HEK293A cells with the addition of cycloheximide, the 3-(4, 5-dimethylthiazol-2-yl)-2, 5-diphenyl tetrazolium bromide (MTT) assay was utilized. The principle of this assay is that the yellow cell-permeable tetrazolium salt MTT is reduced to a blueblack formazan product by living cells. MTT enters the mitochondria of living cells where mitochondrial dehydrogenases reduce this substrate to form the coloured insoluble formazan product. The cells are lyzed and the formazan product is solubilized in dimethyl sulfoxide (DMSO). The blueblack formazan product is then quantified by SpectraMax $340^{\mathrm{PC}}$ microplate reader at a wavelength of $570 \mathrm{~nm}$ with background substraction at $630 \mathrm{~nm}$.

HEK293A cells were placed in a 96-well plate at three different cell densities: $0.2 \times 10^{5}$, $0.5 \times 10^{5}$ and $0.75 \times 10^{5}$ cells $/ \mathrm{mL}$ and incubated in $90 \mu \mathrm{L}$ growth medium with $10 \mu \mathrm{L}$ increasing concentrations of cycloheximide $(0-1,000 \mu \mathrm{g} / \mathrm{mL})$ for 24 hours at $21 \%$ oxygen (normoxic). MTT powder was dissolved in PBS at a concentration of $5 \mathrm{mg} / \mathrm{mL}$, filtered and stored at $4^{\circ} \mathrm{C}$. MTT was added to the wells at a volume equal to one tenth of the original media volume. The plate was further incubated at $37^{\circ} \mathrm{C}$ for 2 hours in a $\mathrm{CO}_{2}$ incubator. Media was replaced with the same volume $(100 \mathrm{uL})$ of DMSO and incubated at room temperature for 10 minutes until the dye was dissolved. The absorbance was measured by SpectraMax340 ${ }^{\mathrm{PC}}$ microplate reader (Molecular Devices, Sunnyvale, CA) at a wavelength of $570 \mathrm{~nm}$ with background absorbance taken at 630 nm. 


\subsection{Human OGFOD1 cloning}

The full length cDNA of OGFOD1 was cloned into pOTB7 vector (Mammalian Gene Collection/Thermo Fisher Scientific/Open Biosystems,Huntsville, AL) The insert was amplified from pOTB7 with PCR and both insert and the vector FLAG-pCR3.1 were digested with enzymes NdeI and ApaI. Digested FLAG-pCR3.1 vector and OGFOD1 insert were ligated together using T4 DNA ligase to generate the final FLAG-OGFOD1-pCR3.1 mammalian expression plasmid. The plasmids were transformed into E.coli DH5 $\alpha$ Library Efficiency competent cells (Invitrogen, Carlsbad, CA). After transformation and isolation of plasmids, constructs were sequenced for proper insert orientation and in-frame insertion with FLAG. Plasmids were purified by Wizard Plus SV Miniprep DNA Purification System (Promega, Madison, USA). The correct plasmids were verified by restriction digestion and sequencing (McGill University and Genome Quebec Innovation Centre, Montreal, QC).

Forward primer: 5'-GTGGCGAACATATGAATGGGAAGCGGCCAGCGG-3'

Reverse primer: 5'GCGGGCCCTCATTCATAATAGATGAATGAAAAGTCCC-3'

\subsection{Site-directed mutagenesis}

Proline 370 of human OGFOD1 was mutated to Alanine (P370A) using the Quick Change Site-Directed Mutagenesis Kit from Stratagene (La Jolla, CA).

Mutagenesis primers were as follows:

Forward Primer: P370A OGFOD1: 5'-CCTGAAGCTTCATTTCTTGGCCGCTT-3'

Reverse Primer: P370A OGFOD1: 5'-CATCTCATCTTCTTCCGAAGCGGCCA-3' 
The resulting clones were verified for the presence of the mutation by sequence analysis (McGill University and Genome Quebec Innovation Centre, Montreal, QC).

\subsection{Transient transfections}

HEK293A cells were plated in antibiotic-free growth medium at a cell density of $2 \times 10^{5}$ cells/mL for 24 hours. The optimal concentration of DNA for transient transfections was determined to be $2.0 \mu \mathrm{g}$ DNA per $1.5 \mathrm{~mL}$ of cells in $10 \mathrm{~cm}$ tissue culture plates. Cells were left for 24 hours

Lipofectamine 2000 (Invitrogen, Carlsbad, CA) was used to carry out transient transfections. According to the manufacturer's protocol, DNA was added to serum-free OptiMEM medium (Gibco, Grand Island, NY) and mixed with Lipofectamine 2000 for 20 minutes. After adding the DNA/Lipofectamine mixture to cells, cells were incubated for 6 hours in normoxia in a $\mathrm{CO}_{2}$ incubator, afterwhich the transfection medium was removed and replaced with normal growth media. At this time, cells were maintained under normoxic conditions for 24 hours to ensure that enough recombinant protein was expressed and then treated with hypoxia or hypoxic mimetics for 6 to 48 hours. Cells were harvested by cell lifter from culture plates, centrifuged at $5,000 \mathrm{Xg}$ for 2 minutes and immediately frozen in liquid nitrogen. Cell pellets were stored at $-80^{\circ} \mathrm{C}$ for further experimentation. 


\subsection{Real-time RT-PCR}

HEK293A cells were seeded into $10 \mathrm{~cm}$ plates at a cell density of $0.1 \times 10^{5}$ cells $/ \mathrm{mL}$ and maintained for 24 hours. Afterwards, cells were treated with normoxia or hypoxia for 24 or 48 hours or proteasome inhibitor (under normoxic conditions) for 6 hours. Total RNA was extracted from cells using RNeasy kit (Qiagen, Missisauga, ON) according to the manufacturer's instructions. The value of $\mathrm{OD}_{260} / \mathrm{OD}_{280} \mathrm{~nm}$ absorption ratio $>1.7$ was used as an indicator of RNA integrity.

One hundred ng of total RNA was reverse transcribed into cDNA and subsequently amplified to DNA in one step using the iScript One-Step RT-PCR Kit with SYBR Green (BioRad, Missisauga, ON). Human OGFOD1 gene-specific primers were produced (Integrated DNA Technologies, Coralville, IA) for the amplification of the target gene (196 bp) as follows:

Forward primer: 5'-ATCAGCAACAACAGCCAACAGAGC-3'

Reverse primer: 5'-AGCCTTCACAGCCACAGTACAGAA-3'

As a control, the housekeeping gene $\beta$-actin (279 bp) was also amplified using the following primers:

Forward primer: 5'-GCGGGAAATCGTGCGTGCATT-3'

Reverse primer. 5'-GATGGAGTTGAAGGTAGTTTCGTG-3'

$\beta$-actin specific primers were generated by Sigma Genosys (Oakville, ON).

Real-time RT-PCR was carried out using the iScript kit, the Rotor-Gene 6000 Real-Time PCR Thermal Cycler (Corbett Research, Concord) and the Rotor-Gene 6000 software (version 1.7). According to the manufacture's protocol, a $50 \mu \mathrm{L}$ reaction mixture included the following components: $25 \mu \mathrm{L} 2$ X SYBR Green RT-PCR Reaction Mix, $1.5 \mu \mathrm{L} 10 \mu \mathrm{M}$ of Forward primer; 
$1.5 \mu \mathrm{L}$ of $10 \mu \mathrm{M}$ Reverse primer; $16 \mu \mathrm{L}$ of nuclease-free $\mathrm{H}_{2} \mathrm{O}, 5 \mu \mathrm{L}$ of $20 \mathrm{ng} / \mu \mathrm{L}$ RNA template and $1 \mu \mathrm{L}$ of iScript Reverse Transcriptase for One-Step RT-PCR. cDNA synthesis from RNA was carried out at $50^{\circ} \mathrm{C}$ for 10 minutes, and then the reverse transcriptase was deactivated at $95^{\circ} \mathrm{C}$ for 5 minutes. RT was followed by PCR using the following parameters: 40 cycles of a) denaturation at $95^{\circ} \mathrm{C}$ for 10 seconds, b) annealing at $60^{\circ} \mathrm{C}$ for 30 seconds and c) extension at $72^{\circ} \mathrm{C}$ for 30 seconds. A final melting curve analysis was performed for 80 cycles at a) $95^{\circ} \mathrm{C}$ for 1 minute, b) $55^{\circ} \mathrm{C}$ for 1 minute and c) $55^{\circ} \mathrm{C}$ for 10 seconds, increasing each by $0.5^{\circ} \mathrm{C}$ each cycle. The critical threshold $(\mathrm{Ct}$; the point at which the fluorescence increased above the background fluorescence of the sample) was obtained by eliminating the first 5 cycles and manually selecting the critical threshold from the linear increasing part of the fluorescence gene expression curve. We presumed the amplification efficiencies of the target and the housekeeping genes to be according to Pfaffl (2001) in which Efficiency $(E)=10^{[-1 / \text { slope }]}=2$. The expression of OGFOD1 (target gene) was quantified according to the Pfaffl method (Pfaffl, 2001). In this mathematical model, the relative expression ratio $(\mathrm{R})$ of a target gene is calculated based on the above efficiency and the deviation of $\mathrm{Ct}$ value of a treated sample from an untreated (control) sample, with normalization to a reference gene according to the following equation:

$$
\text { Ratio }=2^{-\Delta \Delta \mathrm{Ct}}=2^{\Delta \mathrm{Ct} \text { (treated-untreated) }}(\text { sample }) / 2^{\Delta \mathrm{Ct} \text { (treated-untreated) }} \text { (reference gene) }
$$

Total RNA, isolated from cells exposed to normoxic and hypoxic conditions, was designated as untreated and treated samples respectively. 


\subsection{Whole Cell Extract Preparation}

HEK293A cells were grown in $15 \mathrm{~cm}$ plates, exposed to normoxic or hypoxic conditions for 6 to 48 hours and then harvested by washing with ice cold PBS and pelleted by centrifugation at 5,000 X g for 2 minutes at $4^{\circ} \mathrm{C}$. The $50 \mathrm{~mL}$ PBS used for hypoxic samples was previously bubbled by with gaseous nitrogen for 5 mins to remove all traces of oxygen. The cell pellet was lysed in Lysis Buffer (20 mM HEPES (pH 7.9), $420 \mathrm{mM} \mathrm{NaCl}, 1.5 \mathrm{mM} \mathrm{MgCl}, 0.2 \mathrm{mM}$ EDTA, $1 \mathrm{mM}$ DTT, $0.5 \mathrm{mM}$ PMSF and $25 \%$ glycerol) and incubated on ice for 5 minutes. Cell lysates were then centrifuged at $13,000 \mathrm{Xg}$ for 20 minutes. The resulting supernatant was flash frozen in liquid nitrogen and stored at $-80^{\circ} \mathrm{C}$ until use. The protein concentration of whole cell lysates was determined using the Bio-Rad Protein Dye Reagent (Bio-Rad, Missisauga, ON) and using bovine serum albumin as a standard, according the manufacturer's protocol. Protein content was determined using a microplate reader (SpectraMax340 ${ }^{\mathrm{PC}}$ microplate reader (Molecular Devices, Sunnyvale, CA)).

\subsection{Western Blot Analysis}

Cell lysate protein $(5-60 \mu \mathrm{g}$ of protein) from the different treatments was boiled in Laemmli sample buffer (Bio-Rad, Missisauga, ON) containing 5\% $\beta$-mercaptoethanol for 3 minutes at $95^{\circ} \mathrm{C}$. Boiled proteins were then centrifuged at $1000 \mathrm{rpm}$ and then subjected to $8 \%$ (w/v) Sodium Dodecyl Sulfate-Polyacrylamide Gel Electrophoresis (SDS-PAGE) in Running Buffer (25 mM Tris-HCl, $192 \mathrm{mM}$ glycine and $0.1 \% \mathrm{SDS}$ ) at $120 \mathrm{~V}$ for $\sim 1$ hour in a MiniPROTEAN 3 Electrophoresis Cell (Bio-Rad, Missisauga, ON). Proteins were then transferred 
from SDS-PAGE to a Polyvinylidene fluoride (PVDF) membrane (Millipore, Billerica, MA) in Transfer Buffer (20 mM Tris-HCL (pH 8.0), $150 \mathrm{mM}$ glycine and $20 \%$ methanol) overnight at $4^{\circ} \mathrm{C}$ at $180 \mathrm{~mA}$ in a Mini Trans-Blot Cell (Bio-Rad, Missisauga, ON). Non-specific binding of proteins to the membrane was blocked with 5\% non-fat powdered milk dissolved in TBST (20 $\mathrm{mM}$ Tris- $\mathrm{HCl}(\mathrm{pH} 7.6), 137 \mathrm{mM} \mathrm{NaCl}$ and $0.1 \%$ Tween 20) for 1 hour at room temperature. OGFOD1 was detected by incubation with the monoclonal rabbit anti-human OGFOD1, which recognizes the C-terminal residues 398-538 of OGFOD1 (1:4,000 dilution). Beta-tubulin was used as loading control and was detected with a mouse anti-human $\beta$-tubulin antibody (1:2,000 dilution; Developmental Studies Hybridoma Bank, Iowa City, IA). Membranes were probed with primary antibodies for 1 hour at room temperature with slow agitation and then washed six times (5 minutes each) with TBST. Membranes were then incubated with goat anti-rabbit $(1: 2,000$ dilution; Santa Cruz Biotechnology, Santa Cruz, CA) or goat anti-mouse (1:2,000 dilution; Dako, Denmark) horseradish peroxidase-conjugated secondary antibody for 1 hour at room temperature. After secondary antibody treatment, membranes were washed with TBST six times ( 5 minutes each). Membranes were then drained and incubated with Immobilon Western Chemiluminescent HRP Substrate (Millipore, Billerica, MA) to visualize the target proteins. Kodak X-OMAT-AR film was exposed to membranes to detect the signal of the specific proteins bands. Precision Plus Protein Kaleidoscope Standards (Bio-Rad, Missisauga, ON) was used as a reference of protein molecular weights. Protein expression levels were quantified by densitometry (Alpha Ease FC V.3.1.2., Alpha Innotech Co., San Leandro, CA). 


\subsection{Coimmunoprecipitation assays}

FLAG-OGFOD1 expression vectors were transiently transfected into HEK293A cells. Cell pellet collected from $2 \times 15 \mathrm{~cm}^{2}$ flasks were lysed in 330uL Buffer 0.5 (40 mM Tris-HCl (pH 8.0), $10 \mathrm{mM} \mathrm{MgCl} 2,20 \%$ glycerol, $0.2 \%$ Tween 20, $2 \mathrm{M} \mathrm{KCl}, 0.1 \mathrm{M}$ PMSF and inhibitor cocktail tablet (Complete Mini, Roche Diagnostics, Laval, QC)) by pipetting up and down to ensure that cells were completely lysed. The protease inhibitor tablets in Buffer 0.5 inhibit a broad spectrum of serine, cysteine and metalloproteases as well as calpains. Anti-FLAG M2 agarose beads were washed with the $175 \mathrm{uL}$ Buffer 0.5 three times with gently invert. Approximately $330 \mu \mathrm{L}$ Cell lysates were then added to $40 \mu \mathrm{L}$ beads. To ensure maximal binding of FLAG-OGFOD1 to the anti-FLAG beads, samples were slowly rotated overnight at $4^{\circ} \mathrm{C}$. Bound FLAG-OGFOD1was eluted by incubating the beads mixture with FLAG peptide (1 $\mu \mathrm{g} / \mathrm{mL}$ ) in Buffer 0.5 for $40 \mathrm{~min}$ at $4^{\circ} \mathrm{C}$. An anti-FLAG bead with bound FLAG peptide was then removed from the mix by centrifugation at 1,600 rpm for 3 minutes. The supernatant, containing the recombinant protein was stored at $-80^{\circ} \mathrm{C}$ until further use.

\subsection{Statistical analysis}

All results are presented as mean \pm S.E.M of at least three independent experiments. Data analysis was performed by one-way analysis of variance (ANOVA) followed by Tukey's test for multiple comparisons to determine the significance of values between experimental groups, utilizing a statistical software package Origin 7.0 (Originlab Corporation, Northampton, MA). Changes were considered significantly different at a level of $\mathrm{p}<0.05$. 


\section{Results}

\subsection{Database search for LXXLAP subsequence}

Databases of all human proteins (SWISS-PROT and TrEMBL (Boeckmann et al., 2003) was searched for those containing the LXXLAP amino acid sequence by a Perl-based method (Wall, 1987-2001). The list was further narrowed according to a) proteins that occurred in multiple organisms (i.e. phylogenetically conserved), b) proteins that were of known identity, c) proteins with an easily measurable function and d) proteins that could potentially be involved in oxygen-sensing pathways. One interesting candidate was OGFOD1.

Sequence analysis and alignments of the Homo sapiens OGFOD1 homologues with the same protein in a wide range of eukaryotes from fungi to humans (phylogenetically conserved), revealed that OGFOD1 from various organisms contain the same oxygen-dependent sequence of amino acids (LXXLAP) as HIF- $\alpha$ (Figure 8.1). OGFOD1 from various organisms is approximately 550 amino acids long and contain a prolyl 4-hydroxylase (PKHD) domain at the N-terminus (Espenshade et al, 2008) (Figure 8.2). 
Figure 8.1: Multiple alignments of OGFOD1 amino acid sequences from multiple organisms: showing conservation of the LXXLAP sequence in OGFOD1. 
Human OGFOD1 Mouse OGFOD1

Bovine OGFOD1
LXXIAP

351 EALFLLLSNFTGLKLHFLAPSEEDEMNDKK 380 351 EALFLLLSNLTGLKLHFLAPSEDDETEEKG 380 351 EAMFLLLSNFTGLKLHFLAPSEDEPEDKKE 380 351 EALFLLLSNETGLKLHFLAPSEEDEMNDKK 380 383 TSSLFDKLKKEPDALTLLAPAAGDTIISLD 412 545 EAKNPFSTQDTDLDLEMLAPYIPMDDDFQL 580
Human HIF-1 alpha (1)

Human HIF-1 alpha (2) 


\subsection{Changes in endogenous OGFOD1 protein levels in response to hypoxia}

To investigate whether an increased expression of the OGFOD1 protein under hypoxic conditions occurs, OGFOD1 protein levels during normoxic and hypoxic conditions were analyzed in whole cell extracts from HEK293A lysates using Western blots and a specific antibody to the C-terminal residues 398-538 of OGFOD1. OGFOD1 expression were same under either normoxic or hypoxic conditions. The changes in the levels of OGFOD1 were normalized to the levels of $\beta$-tubulin, which was used as a loading control, and detected at $55 \mathrm{kDa}$ by an antitubulin antibody.

Densitometry revealed that OGFOD1 protein levels do not significantly change in response to hypoxia compared to normoxia (Figure 8.3). No significant changes in OGFOD1 protein expression occurred with either hypoxia or hypoxic mimetics, compared to normoxia. The ANOVA followed by Tukey's test demonstrated that there were no significant changes in OGFOD1 protein expression between any of the treatments. Theses results indicate that OGFOD1 protein expression is not regulated in an oxygen-dependent manner. 
Figure 8.3: Effect of hypoxia on OGFOD1 protein expression in HEK293A cells. Cells were treated with normoxia $\left(21 \% \mathrm{O}_{2}, 5 \% \mathrm{CO}_{2}, 37^{\circ} \mathrm{C}\right)$, hypoxia $\left(1 \% \mathrm{O}_{2}, 5 \% \mathrm{CO}_{2}, 37^{\circ} \mathrm{C}\right)$ or hypoxic mimetics $\left(\mathrm{CoCl}_{2}, 100 \mu \mathrm{M}\right.$ for $24 \mathrm{~h}$; DFO, $100 \mu \mathrm{M}$ for $24 \mathrm{~h}$; proteasome inhibitor, MG132, 10 $\mu \mathrm{M}$ for 6 hours) under normoxic conditions. A) Anti-OGFOD1 (top panel) and anti-tubulin (bottom panel) showing expression level of OGFOD1 protein in HEK293A cells under the various treatments. B) Densitometry of Figure 1A. Data represent means \pm S.E.M. of five independent experiments. 
A

$\begin{array}{lllllll}1 & 2 & 3 & 4 & 5 & 6 & 7\end{array}$

Normoxia (h) $48-\quad-\quad-2466$

Hypoxia (h) - $\begin{array}{lllllll} & 6 & 24 & 48 & - & - & -\end{array}$

Cobalt (h) - - - - $24-$

$\mathrm{DFO}(\mathrm{h})$ - - - - - 6 -

$\mathrm{PI}(\mathrm{h})_{100-}---\infty-6$

$75-$

$50-$

B

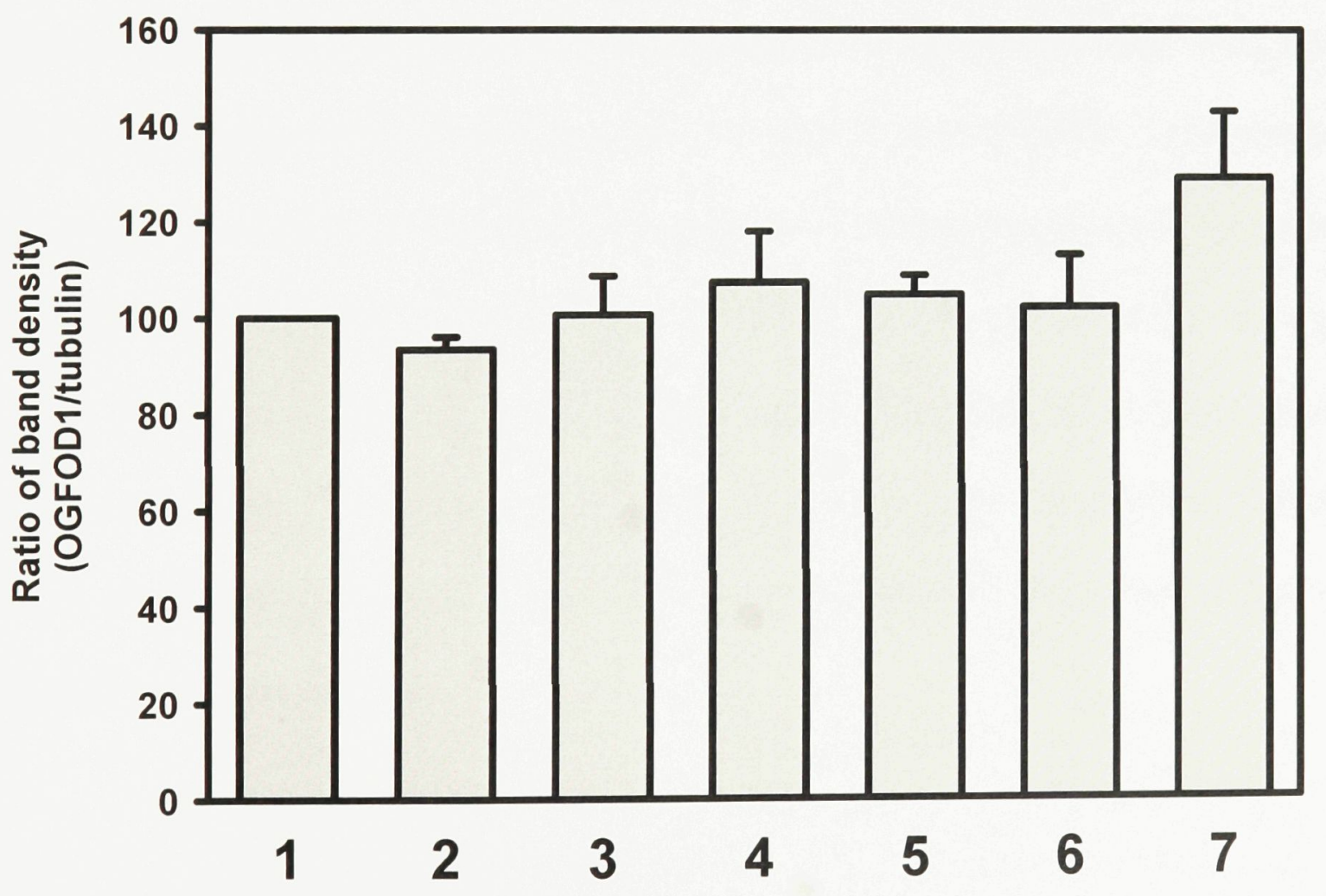




\subsection{OGFOD1 gene expression level in response to hypoxia}

To examine whether OGFOD1 gene levels change during hypoxia in HEK293A cells, a quantitative real-time PCR analysis was used. Total RNA from normoxic and hypoxic HEK293A cells was reverse transcribed to cDNA by reverse transcription and subsequent PCR and OGFOD1 gene-specific primers. Real-time RT-PCR analysis determined OGFOD1 gene expression relative to $\beta$-actin.

Analysis of amplification products from real-time RT-PCR revealed amplicons of the correct molecular weights (196 and 279 bp for OGFOD1 and $\beta$-actin respectively) (Figure 8.4B). The $\beta$-actin gene was used as an internal reference gene for real-time RT-PCR as the levels of this mRNA remained unchanged in all samples with different treatments. A melting curve analysis was performed for all samples to confirm the specificity of the primers used and resulted in single product melting temperatures (approximately $94^{\circ} \mathrm{C}$ for OGFOD 1 and $93^{\circ} \mathrm{C}$ for $\beta$-actin; data not shown). Figure 8.4A presents the levels of OGFOD1 in HEK293A cells normalized by the amount of $\beta$-actin and expressed as fold changes over controls (normoxia). Quantitative realtime RT-PCR and the Pfaffl method (Pfaffl, 2001) was used to analyze the genes expression level. OGFOD1 gene expression does not significantly change during hypoxic condition as compared to normoxia. The ANOVA and Tukey's tests for multiple comparisons indicated that there were no significant changes in OGFOD1 gene expression between each of the normoxic and hypoxic conditions $(\mathrm{p}>0.05)$. 


\section{Figure 8.4: Quantitative real-time RT-PCR analysis of OGFOD1 gene expression in}

HEK293A cells. HEK293A cells were treated with hypoxia $\left(1 \% \mathrm{O}_{2}, 5 \% \mathrm{CO}_{2}, 37^{\circ} \mathrm{C}\right)$ for 24 and 48 hours and proteasome inhibitor $(10 \mu \mathrm{M})$ for 6 hours. Total RNA from HEK293A cells was reverse transcribed using gene-specific primers for human OGFOD1 or the housekeeping gene human $\beta$-actin. The resulting cDNAs were amplified by real-time PCR. The procedure of cDNA was reverse transcribed from RNA and amplified to DNA in the same. A) Changes in OGFOD1 gene expression quantified by real-time RT-PCR. The level of OGFOD1, was normalized by the amount of $\beta$-actin and expressed as a percentage of normoxic controls. Data is presented as means \pm S.E.M from four independent experiments. Statistical analysis by ANOVA and Tukey's tests demonstrated that there were no significant differences in OGFOD1 gene expression between normoxic and hypoxic conditions $(\mathrm{p}>0.05)$. B) To confirm the specificity and purificity of the PCR product, analysis OGFOD1 and $\beta$-actin gene products resolved via agarose gel electrophoresis. Products of the correct molecular weight were amplified (OGFOD1 with a 196 bp product and $\beta$-actin with a 279 bp product). $N=48$ hours normoxic, $\mathrm{H}=24$ or 48 hours hypoxic, $\mathrm{PI}=$ protesome inhibitor 6 hours. 
A

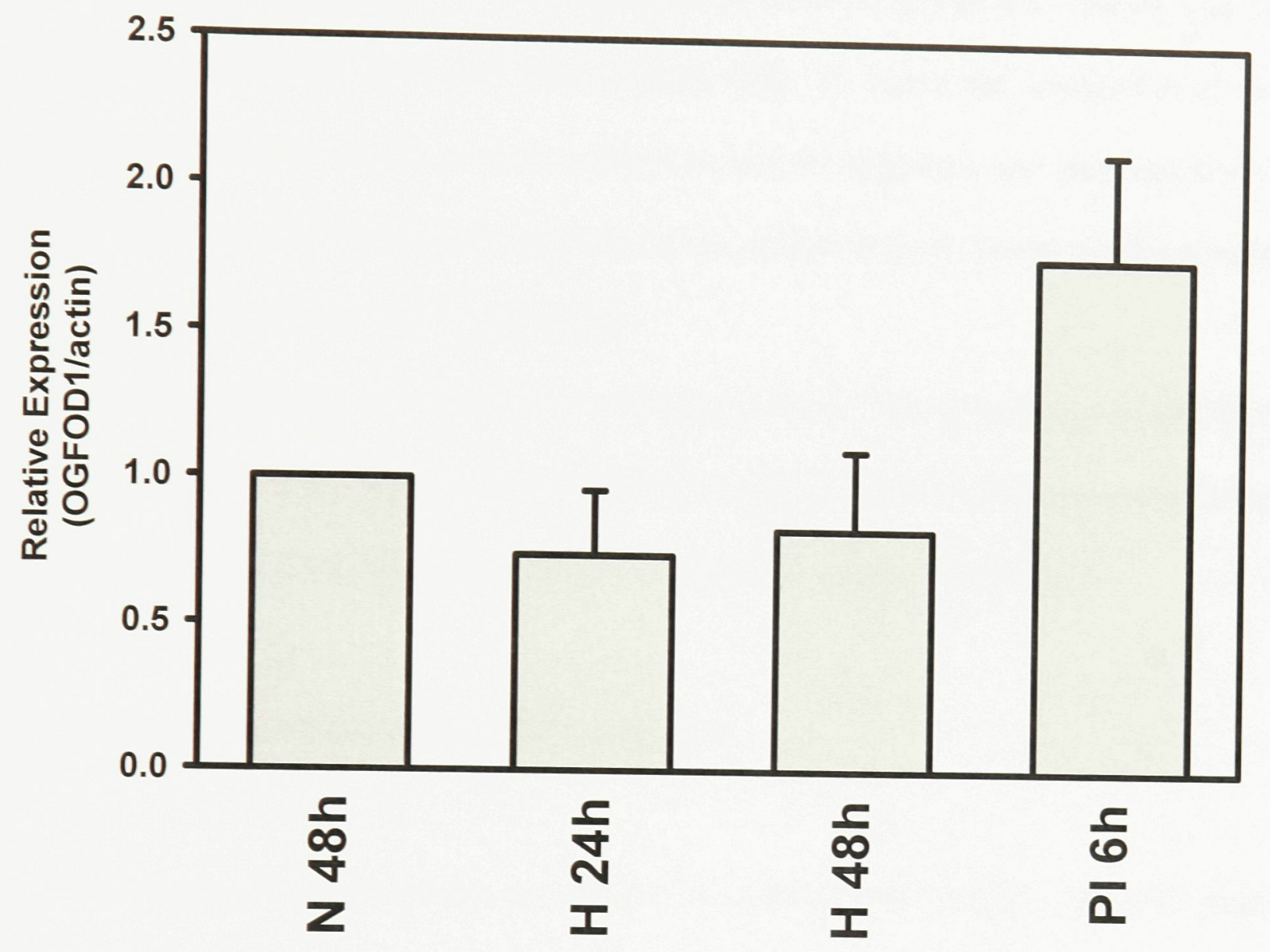

B

N 24h H 48h H 6h PI

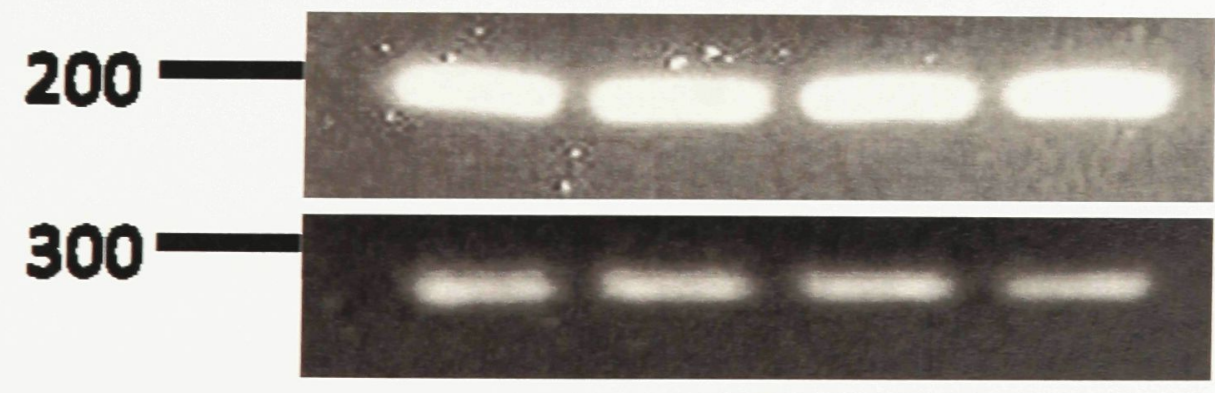




\subsection{Cloning, tagging and expression of recombinant OGFOD1}

The correct ligation of the OGFOD1 gene into the FLAG-pCR3.1 vector was verified restriction digestion with ApaI and NdeI (Figure 8.5). To check the orientation of insert is correct ligated with the vector, another restriction enzyme digestion was performed by EcoRI and ScaI. Sequencing of the construct provided final confirmation of correct cloning (orientation, in-frame, etc.) of OGFOD1 into FLAG-pCR3.1.

The point mutation of Proline 370 to Alanine of the LXXLAP sequence in OGFOD1 was performed using the QuikChange Site-Directed Mutagenesis Kit from Stratagene (La Jolla, CA). Sequencing provided final confirmation of correct P370A mutation in OGFOD1.

\subsection{Cell viability with cycloheximide treatment}

To completely inhibit protein synthesis, but maintain cell viability, the MTT assay was utilized to examine the effects of treating HEK293A cells with different concentrations of cycloheximide over 24 hours. This colorimetric method determines cell viability using MTT [3(4,5-dimethylthiazol-2-yl)-2,5-diphenyltetrazolium bromide] and proved to be more accurate and timesaving than the conventional hemocytometer counting method with Trypan Blue.

HEK293A cells were plated at three different cell densities: $0.2 \times 10^{5} ; 0.5 \times 10^{5}$ and $0.75 \times 10^{5}$ cells $/ \mathrm{mL}$, and incubated with cycloheximide for 24 hours. Cell viability decreased as the concentration of cycloheximide increased (Figure 8.6). Different cell densities did not significantly affect the toxic cycloheximide concentration to cells; the curve only shifted 
Figure 8.5: Diagnostic restriction enzyme digestion. A) Diagnostic restriction enzyme digestion for the verification of ligation of N-terminal FLAG tagged OGFOD1 into the ApaI/NdeI site of the vector; Lane 1: the OGFOD1 PCR product after digestion with NdeI and ApaI; Lane 2: FLAG-pCR3.1 vector after digest with NdeI and ApaI; Lane 3: final construct digested with NdeI and ApaI showing both vector and insert; B) Restriction enzyme digestion with EcoRI and ScaI; Lane 1: undigested FLAG-OGFOD1-pCR3.1 vector; Lane 2 \& 3: FLAGOGFOD1-pCR3.1 vector was digested by EcoRI/ScaI to check for the correct insertion of the human OGFOD1 mRNA. 
A

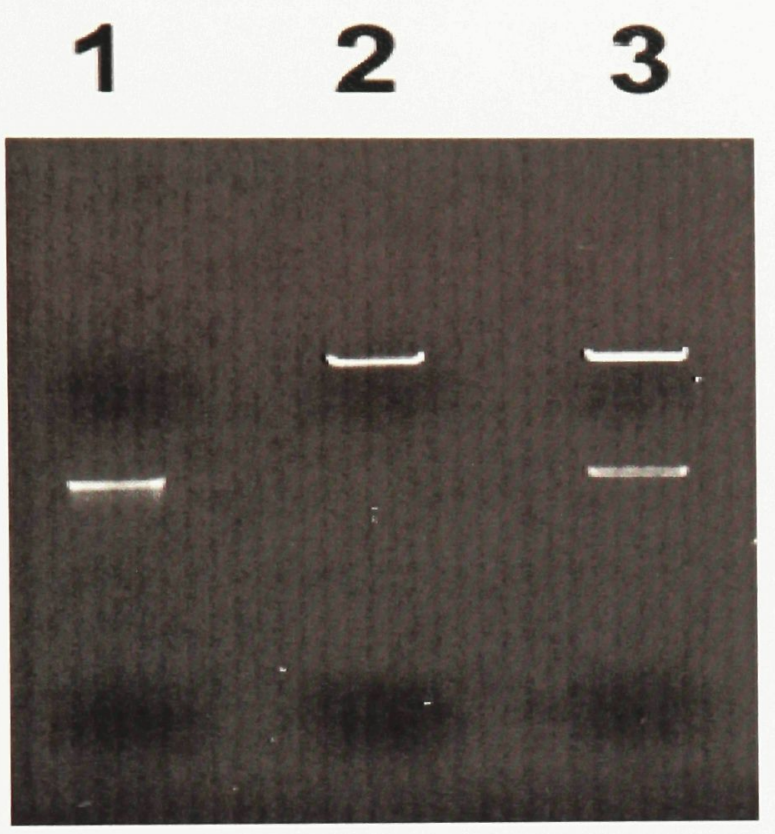

B

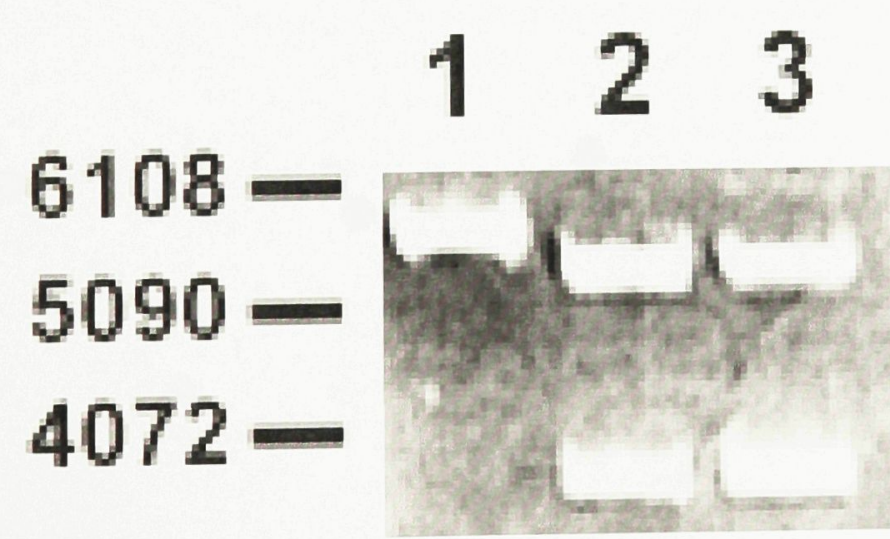


Figure 8.6: Cell viability (as measured by MTT) with the addition of increasing amounts of cycloheximide to HEK293A cells in their exponential growth phase over 24 hours of treatment at different cell densities: $0.2,0.5$ and $0.75 \times 10^{5}$ cells $/ \mathrm{mL}$. 


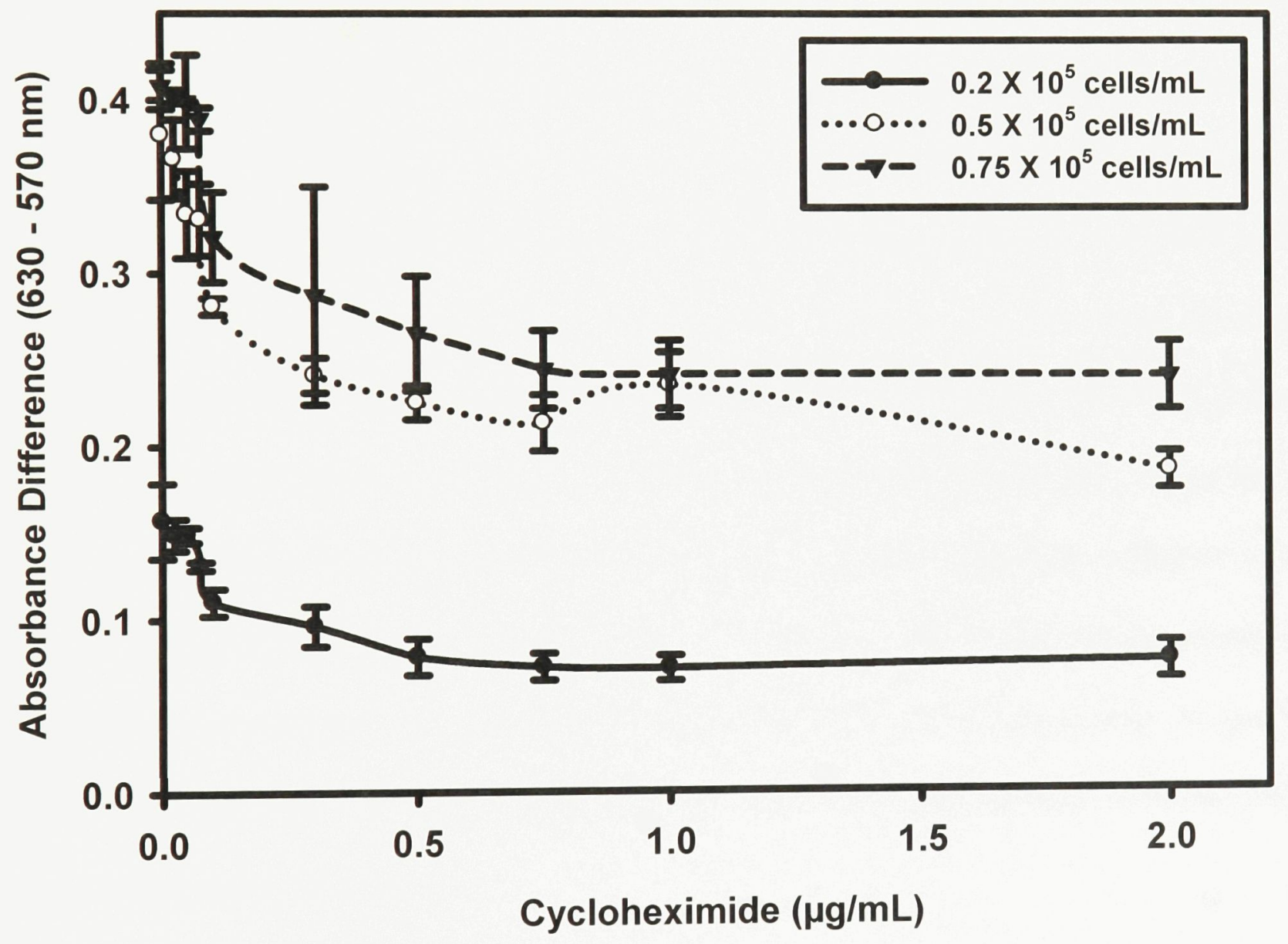


upwards as the initial formazan absorbance increased. At a cycloheximide concentration of 0.1 $\mu \mathrm{g} / \mathrm{mL}$, cell viability decreased to approximately $50 \%$ of initial (untreated) values $\left(\mathrm{IC}_{50}\right) . \mathrm{A}$ cycloheximide concentration at $0.05 \mu \mathrm{g} / \mathrm{mL}$ was then chosen for protein synthesis inhibition experiments.

\subsection{Protein synthesis inhibition studies}

Protein degradation of overexpressed wildtype and mutant OGFOD1 was followed over time in HEK293A cells treated with cycloheximide to inhibit protein translation under different oxygen regimes. Figure 8.7A shows the Western blots of FLAG-tagged wildtype or P370A mutant OGFOD1 under normoxic or hypoxic conditions after inhibition of protein synthesis. OGFOD1 expression was normalized to $\beta$-tubulin expression on the same Western blot. Approximately $40 \%$ of either wildtype or mutant OGFOD1 was degraded after $48 \mathrm{~h}$ of normoxic or hypoxic cycloheximide treatment. As illustrated in Figure 8.7B, the turnover of the mutant protein was same as wildtype under both normoxic and hypoxic conditions. Mutation of Proline 370 in the LXXLAP sequence did not change the stability of OGFOD1 under normoxia with cycloheximide treatment. The half-life of FLAG-OGFOD1 was approximately 50 hours. This result shows that the LXXLAP sequence is not involved in the stability of FLAG-OGFOD1 under either normoxia or hypoxia. 
Figure 8.7: Effect of hypoxia on OGFOD1 protein degradation in HEK293A cells: A) AntiFLAG (top panel) and anti-tubulin (bottom panel) Western blot of wildtype (WT) and mutant (P370A; MUT) FLAG-OGFOD1 overexpressed in HEK293A cells over time and normalized to $\beta$-tubulin protein expression. Mammalian expression vectors containing wildtype or mutant OGFOD1 constructs were transiently transfected into HEK293A cells and treated with normoxia $\left(21 \% \mathrm{O}_{2}, 5 \% \mathrm{CO}_{2}, 37^{\circ} \mathrm{C}\right)$, hypoxia $\left(1 \% \mathrm{O}_{2}, 5 \% \mathrm{CO}_{2}, 37^{\circ} \mathrm{C}\right)$. Cycloheximide $(0.05 \mu \mathrm{g} / \mathrm{mL})$ was used in each treatment to inhibit protein synthesis B) The relative amount of wildtype and mutant OGFOD1 at each time point was plotted as the percentage of the amount at time zero. Data is presented as means \pm S.E.M from 4 independent experiments. 
A
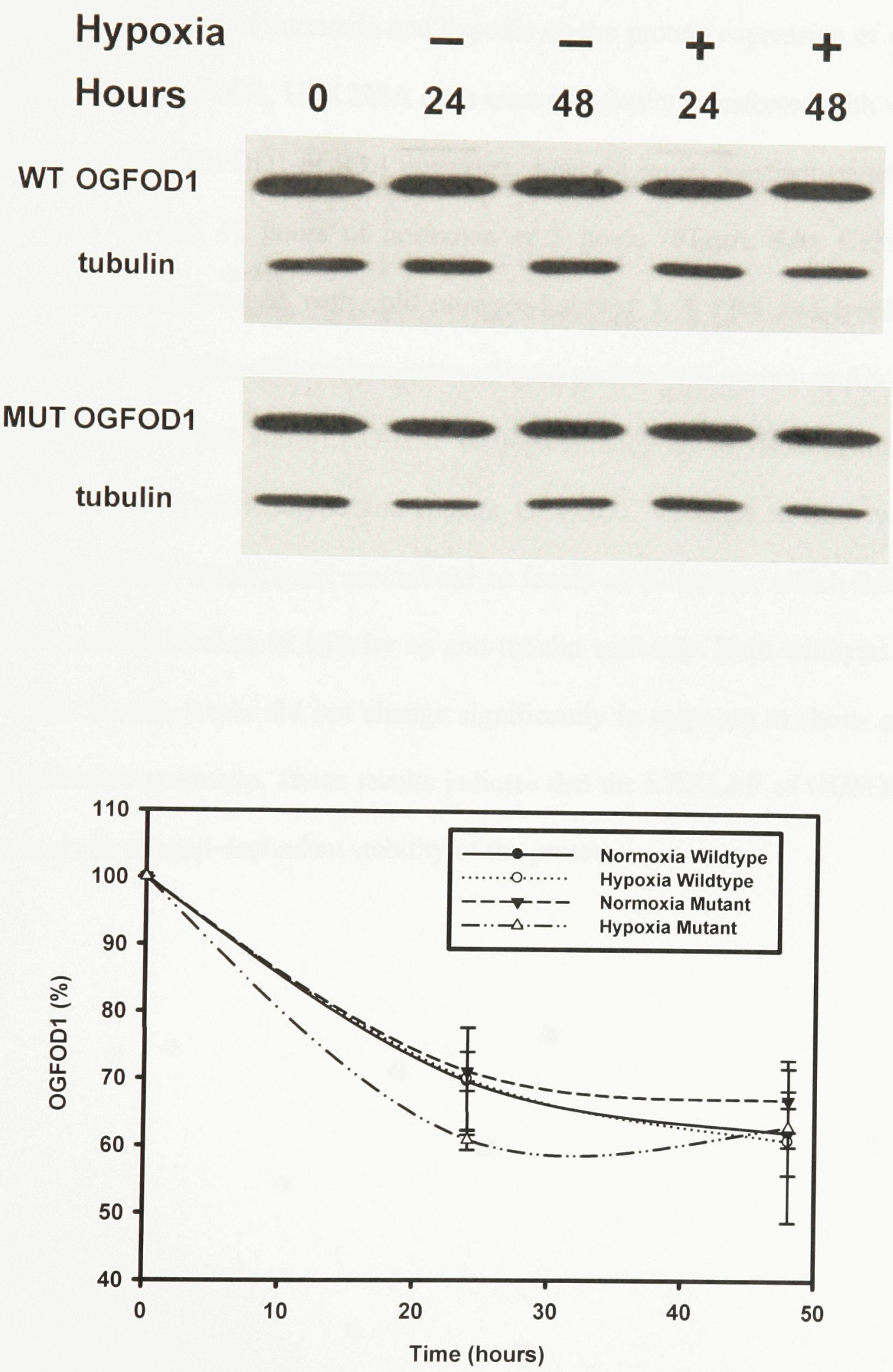


\subsection{Effects of normoxia and hypoxia on recombinant wildtype and mutant OGFOD1}

To observe the effect of normoxia and hypoxia on the protein expression of wildtype and mutant P370A FLAG-OGFOD1, HEK293A cells were transiently transfected with wildtype and mutant (P370A) FLAG-OGFOD1-pCR3.1 construct. After 24 hours transient transfection, cells were treated with 24 and 48 hours of normoxia or hypoxia (Figure 8.8). Cells were then harvested by cell lifting, washed with cold nitrogen-bubbled 1 X PBS and lysed using cold nitrogen-bubbled Lysis Buffer. Five micrograms of total protein was run on an $8 \%$ SDS-PAGE gel and Western blotted using anti-FLAG-HRP conjugated antibody to visualize the differences between expression level of wildtype and mutant OGFOD1. Changes in both wildtype and

mutant FLAG-OGFOD1 levels were normalized to levels of $\beta$-tubulin, which was used as a loading control and detected at $55 \mathrm{kDa}$ by an anti-tubulin antibody. Both wildtype and mutant FLAG-OGFOD1 protein levels did not change significantly in response to short- or long-term hypoxia, compared to normoxia. These results indicate that the LXXLAP of OGFOD1 may not play a central role in oxygen-dependent stability of the protein. 
Figure 8.8: Western blot of transiently transfected wildtype and mutant (P370A) of Nterminally FLAG-tagged human OGFOD1 overexpressed in HEK293A cells with 24 and 48 hours of hypoxia treatment. Western blot with anti-FLAG-HRP conjugated antibody. Lane 1: P370A mutant; Lane 2: wildtype FLAG-OGFOD1; Lane 3: P370A mutant with 24 hours of hypoxia treatment; Lane 4: wildtype FLAG-OGFOD1 with 24 hours of hypoxia treatment; Lane 5: P370A mutant with 48 hours of hypoxia treatment; Lane 6: Wildtype FLAG-OGFOD1 with 48 hours of hypoxia treatment. FLAG-OGFOD1 (upper panel) with the correct molecular weight (approximately $63 \mathrm{kDa}$ ) and the $\beta$-tubulin (bottom panel) with the correct molecular weight (53 $\mathrm{kDa}$ ) are indicated. 
Mutant

Wildtype

Hypoxia

Hours

OGFOD1 $75-$

tubulin $50-$ $\begin{array}{llllll}1 & 2 & 3 & 4 & 5 & 6\end{array}$

$+-+-+-$

$-+-+-+$

$-\quad+\quad+\quad+$

$\begin{array}{llllll}48 & 48 & 24 & 24 & 48 & 48\end{array}$ 


\subsection{Protein expression of mature and precursor forms of SREBP1 with overexpression of wildtype and P370A mutant OGFOD1 under hypoxia.}

It is known that the C-terminal domain of the yeast form of OGFOD1 (Ofd1) interacts with the yeast form of SREBP1 (Sre1) (Espenshade, 2008). This is known to be regulated by the binding of yeast protein Nro1 to the C-terminus of Ofd1 (Espenshade, 2009). There is no known mammalian equivalent of Nro1. Since oxygen did not affect the stability of OGFOD1, the possibility that oxygen affects the interaction of OGFOD1 with SREBP1 was investigated.

The effect of overexpression of the wildtype and mutant OGFOD1 on the protein expression levels of both the precursor and mature forms of SREBP1, under normoxic and hypoxic conditions, was detected by Western blotting with anti-SREBP1 antibody. In the endogenous HEK293A cells, with 48 hours of hypoxia, the mature form of SREBP1 (SREBP1N) significantly increased (approximately 2-fold) while the precursor of SREBP1 (SREBP1P) significantly decreased (also approximately 2 -fold) compared to normoxia (Figure 8.9B). In HEK293A cells, transfected with wildtype FLAG-OGFOD1 under normoxia, SREBP1N significantly increased 4-fold compared to endogenous expression levels under normoxia, while SREBP1P significantly decreased approximately 2-fold compare to endogenous levels (Figure 8.9B). However, when comparing the levels of SREBP1N between normoxia and hypoxia at 48 hours in cells transfected with wildtype OGFOD1, SREBP1N protein was 2-fold greater under hypoxia than under normoxia (Figure 8.9B). The fold increases in SREBP1 caused by with or without overexpression of wildtype or mutant OGFOD1 under hypoxia are same; revealing that 
Figure 8.9: Protein expression level of SREBP1 was measured from HEK293A cells after transfection with wildtype (WT) and site-directed mutants (P370A) (MUT) of OGFOD1 under 24 or 48 hours of normoxia or hypoxia. A, C) HEK293A cells were transfected with either wildtype or P370A mutant FLAG-OGFOD1. Twenty four hours after transfection, HEK293A (Endo) and HEK293A with overexpression of either wildtype (WT) or mutant (P370A) (MUT) FLAG-OGFOD1 were treated with normoxia $\left(21 \% \mathrm{O}_{2}\right)(\mathrm{N})$ or hypoxia $\left(1 \% \mathrm{O}_{2}\right)$ (H) for 48 and 24 hours. Whole cell extracts were subjected to Western blot analysis using antiSREBP1 (upper panel) (could detect both precursor (SREBP1P) and mature form of SREBP1 (SREBP1N), anti-FLAG (middle panel) or anti- $\beta$-tubulin (bottom panel) as indicated. Lane 1: untransfected HEK293A treated with normoxia for 48 and 24 hours (control); Lane 2: untransfected HEK293A treated with hypoxia for 48 and 24 hours; Lane 3: HEK293A transfected with wildype FLAG-OGFOD1 and treated with normoxia for 48 and 24 hours; Lane 4: wildtype FLAG-OGFOD1 transfected into HEK293A treated with hypoxia for 48 and 24 hours; Lane 5: HEK293A transfected with mutant (P370A) FLAG-OGFOD1; Lane 6: mutant (P370A) FLAG-OGFOD1 transfected into HEK293A treated with hypoxia for 48 and 24 hours;

B, D) Densitometry of Figure 8.9A and C were analyzed by AlphaEase FC v.3.1.2. (Alpha Innotech Co., San Leandro, CA). Data represent means \pm S.E.M. from five independent experiments with $*=\mathrm{p}<0.05$ compared to normoxia. 
A

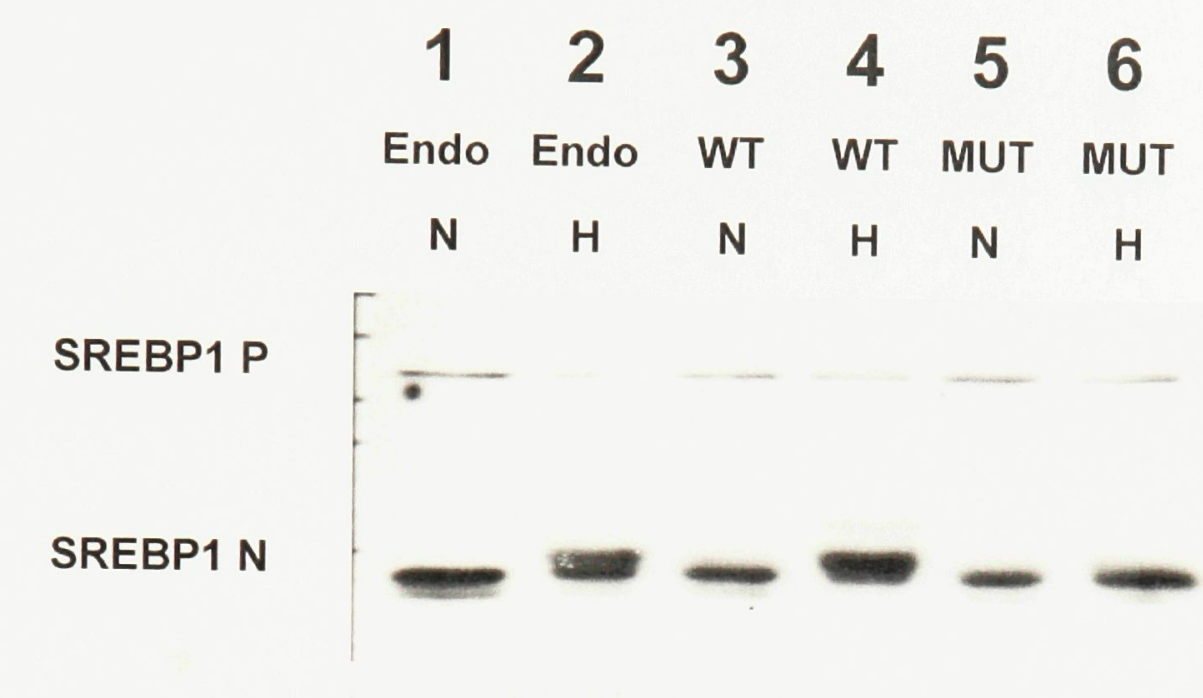

FLAG

actin

B

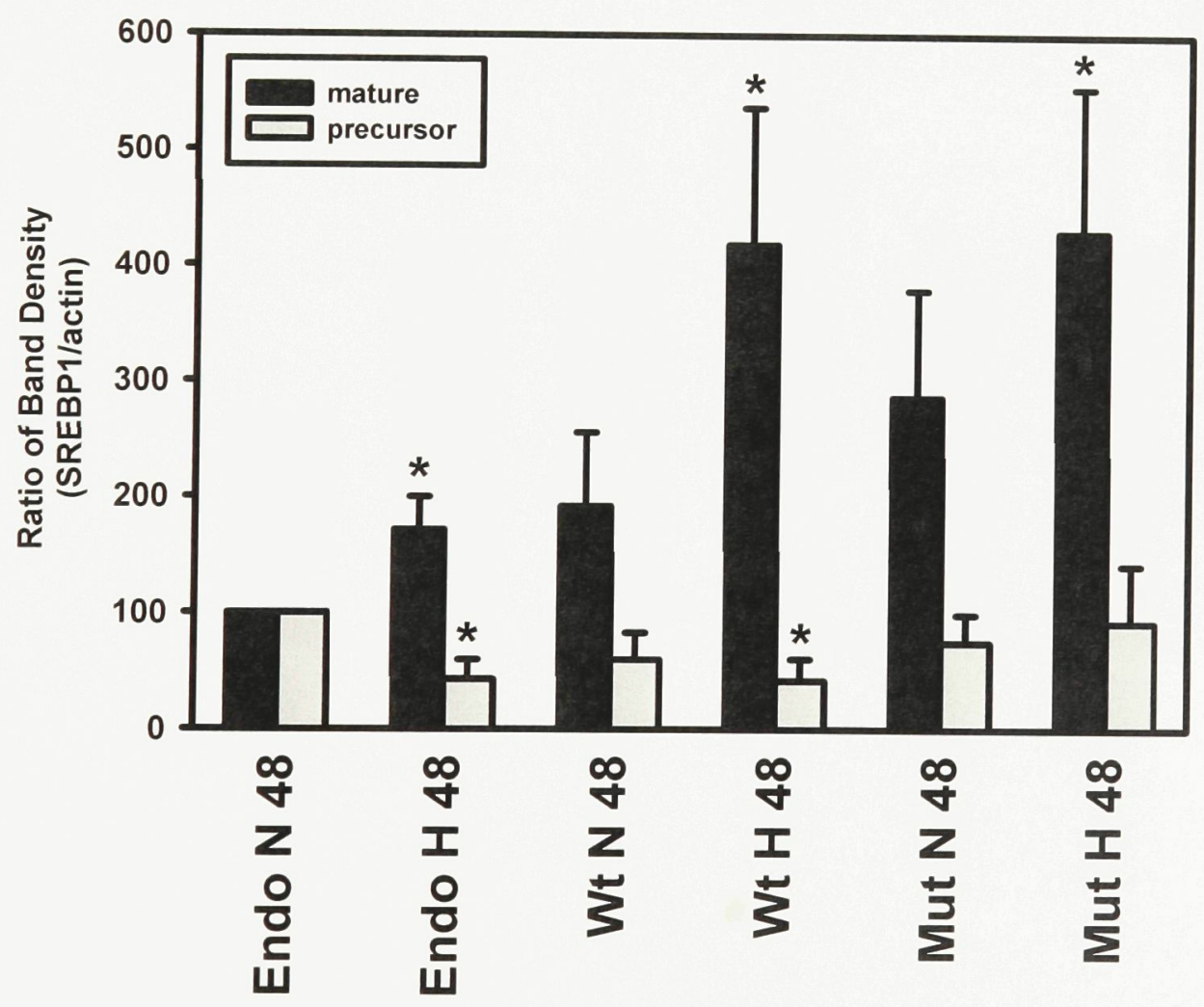


C

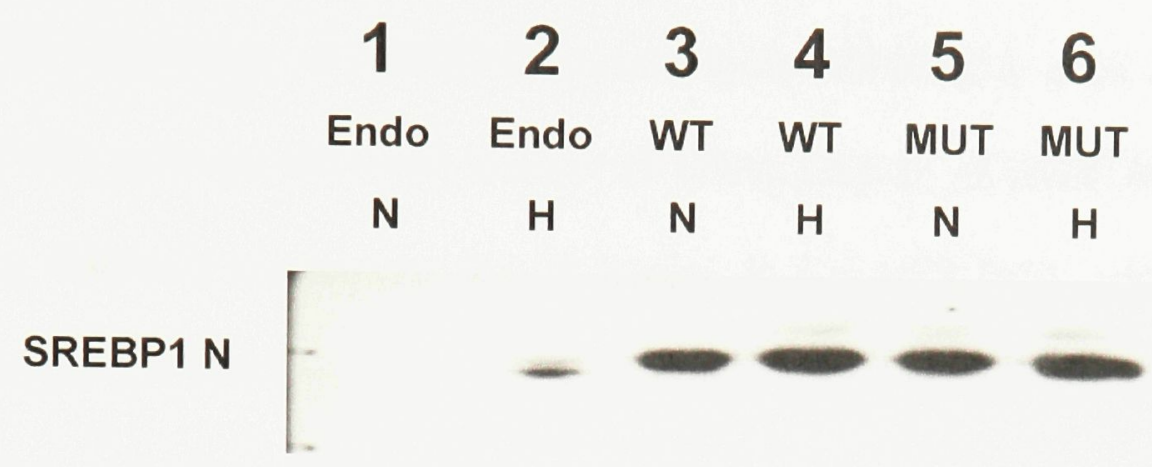

FLAG

actin

D

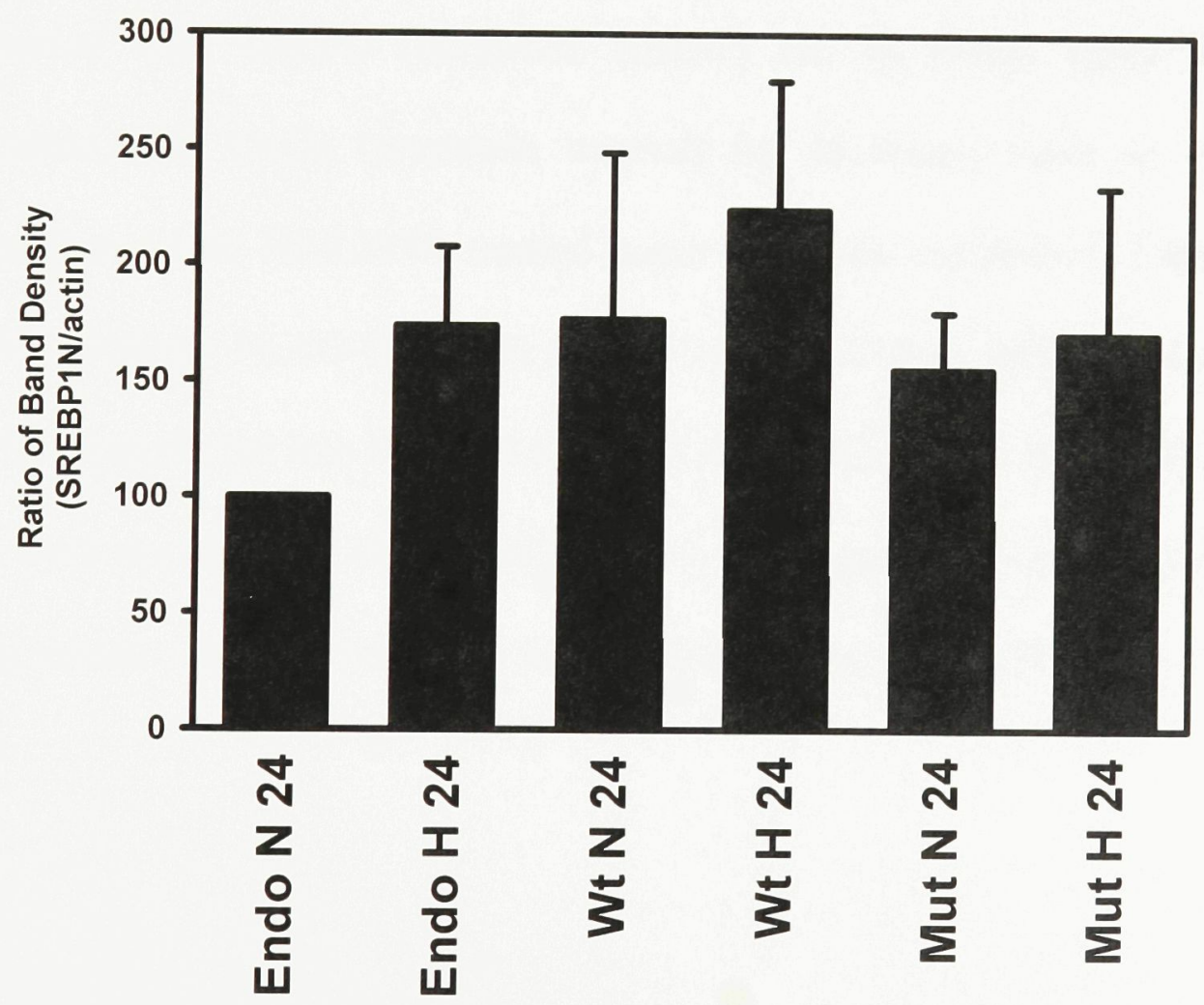


Figure 8.10: The expression of SREBP1 protein from HEK293A cells after transfection with wildtype (WT) and site-directed mutant (P370A) (MUT) of OGFOD1 under hypoxic mimetic ( $\mathbf{C o C l}_{2}$; DMOG) treatments for $\mathbf{4 8}$ hours. A, C). HEK293A cells were transfected with either wildtype or P370A mutant FLAG-OGFOD1. Twenty four hours after transfection, HEK293A (Endo) and HEK293A with overexpression of either wildtype (WT) or mutant (P370A) (MUT) FLAG-OGFOD1 were treated with treated for 48 hours with DMSO (vehicle of DMOG), $1 \mathrm{mM}$ DMOG or $100 \mu \mathrm{M} \mathrm{CoCl} 2$ (CC). Whole cell extracts were subjected to Western blot analysis using anti-SREBP1 (upper panel) (could detect both precursor (SREBP1P) and mature form of SREBP1 (SREBP1N), anti-FLAG (middle panel) or anti- $\beta$-tubulin (bottom panel) as indicated. Lane 1: untransfected HEK293A (positive control); Lane 2: untransfected HEK293A treated with DMOG (normoxic control) for 48 hours; Lane 3: untransfected HEK293A treated with $\mathrm{CoCl}_{2}$ (normoxic control) for 48 hours; Lane 4: wildtype FLAGOGFOD1 transfected into HEK293A treated under normoxic conditions; Lane 5: HEK293A transfected with wildtype FLAG-OGFOD1 treated with DMOG for 48 hours; Lane 6: Wildtype FLAG-OGFOD1 transfected into HEK293A treated with $\mathrm{CoCl}_{2}$ for 48 hours; B) Densitometry of Figure 8.10A were analyzed by AlphaEase FC v.3.1.2. (Alpha Innotech Co., San Leandro, CA). Data represent means \pm S.E.M. from five independent experiments with $*=p<0.05$ compared to normoxia. 
A
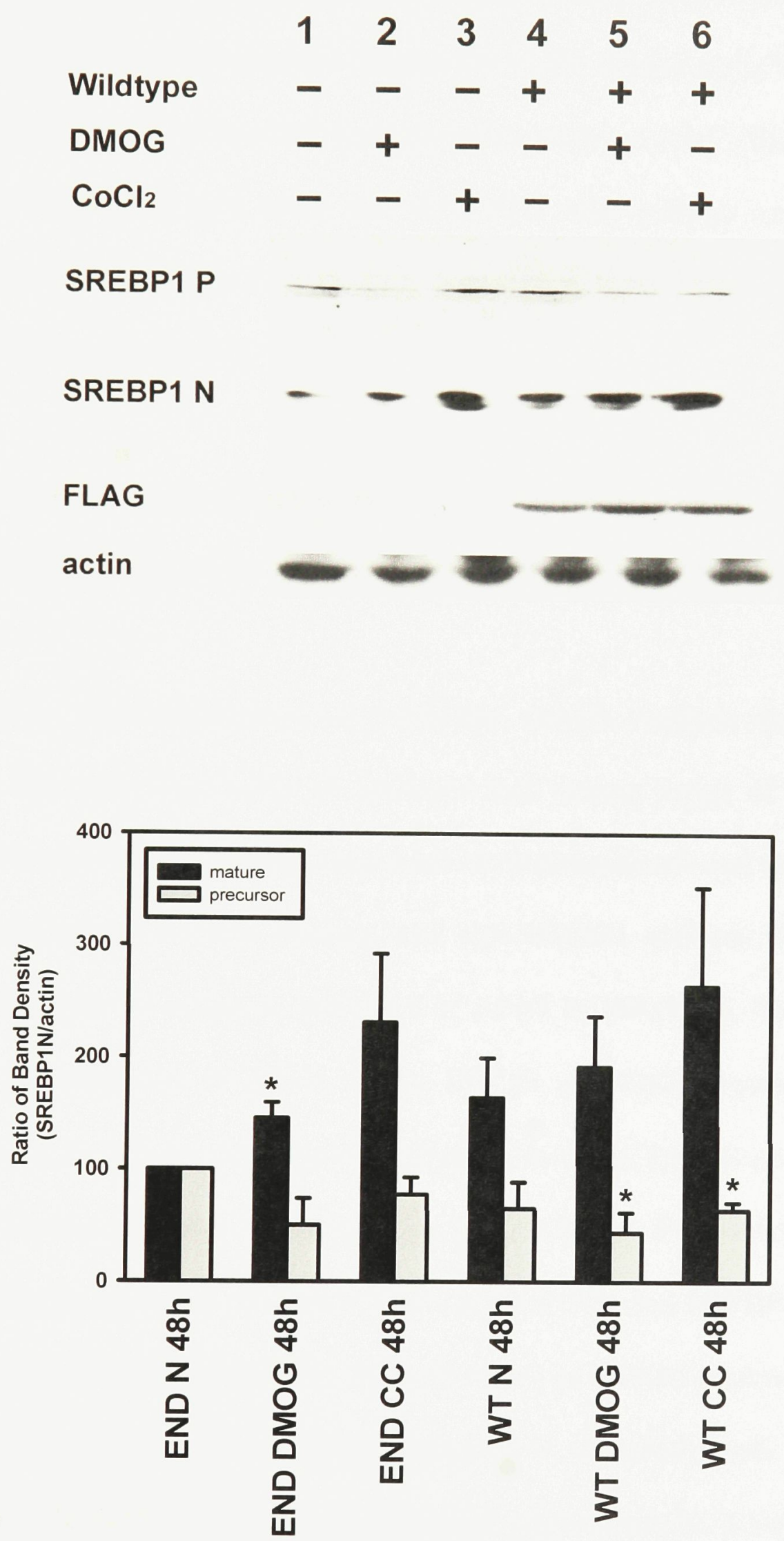
overexpression of FLAG-OGFOD1 did not have significant effects on the expression of SREBP1N under either normoxia or hypoxia at 48 hours. With 24 hours treatment, there were no significant changes of SREBP1N detected (Figure 8.9 C, D). Interestingly, SREBP1N showed a doublet band under hypoxia with either endogenous or overexpressed wildtype OGFOD1, but not mutant OGFOD1. This may mean that SREBP1N may undergo an oxygen-dependent posttranslational modification that is dependent upon the LXXLAP sequence of OGFOD1. This result requires further investigation.

\subsection{Expression of mature and precursor forms of SREBP1 protein with overexpression of wildtype OGFOD1 under treatment with prolyl hydroxylase inhibitors.}

To examine if overexpression of OGFOD1 (which contains the PKHD domain) correlated with the expression levels of precursor and mature forms of SREBP1, hypoxic mimetics (DMOG and cobalt chloride) were used on nontransfected and transfected cells and SREBP1 was detected by Western blotting with anti-SREBP1 antibody. DMOG and cobalt chloride mimic hypoxia by acting as inhibitors of prolyl hydroxylases, the enzymes that are responsible for hydroxylation of HIF- $\alpha$. Under DMOG and $\mathrm{CoCl}_{2}$ treatment, the levels of SREBP1N would be expected to increase significantly. However, DMOG and $\mathrm{CoCl}_{2}$ could also inhibit the PKHD domain function of the overexpressed OGFOD1. Figure 8.10 show the effects of hypoxic mimetic treatment on the levels of FLAG-OGFOD1 and SREBP1N. The first three lanes show untransfected HEK293A cells. With 48 hours of DMOG treatment, the SREBP1N significantly increase approximately 1.5 -fold, compared to untreated levels. With 48 hours of $\mathrm{CoCl}_{2}$ treatment, SREBP1N significantly increased approximately 2.3 -fold, compared to 
normoxia. The precursor of SREBP1 decreased with DMOG and CoCl2 treatment compared to normoxia, while the active form of SREBP1 (SREBP1N) increased. When comparing the levels of the SREBP1N protein between normoxic transfected cells to normoxic untransfected cells, transfected cells had approximately 1.5 -fold more SREBP1N than untransfected cells. SREBP1N increased approximately 2-fold in transfected cells with DMOG treatment in comparison to untransfected cells. SREBP1N levels in transfected cells treated with $\mathrm{CoCl}_{2}$ increased by 2.5 -fold compared to untransfected cells. With the increase of SREBP1N in transfected HEK293A cells came with a decrease in SREBP1P. With overexpression of OGFOD1, SREBP1P decreased approximately 1.6 -fold compared to the level of endogenous SREBP1P under normoxic conditions. In transfected HEK293A cells, with DMOG and $\mathrm{CoCl}_{2}$ treatment, SREBP1P significantly decreased approximately 2 -fold and 1.8 -fold respectively compared to normoxic untransfected cells. With transfection, SREBP1N increased approximately 1.3 -fold and 1.6-fold with normoxic DMOG and $\mathrm{CoCl}_{2}$ treatments respectively while SREBP1N decreased approximately 1.1 -fold. These results suggest that the PKHD domain of overexpressed OGFOD1 does not appear to have an effect on SREBP1 expression in comparison to the endogenous expression of OGFOD1.

\subsection{The potential interaction between SREBP1 and OGFOD1}

To test if there is direct or indirect interaction between SREBP1 and OGFOD1, coimmunoprecipitation of SREBP1 (either form) with FLAG-OGFOD1 was attempted. Figure 8.11 shows the coimmunoprecipitation of SREBP1 with OGFOD1 using Western blots probed with either anti-SREBP or anti-FLAG antibodies. The first three lanes show the 
immunoprecipitation of OGFOD1 by anti-FLAG beads and Western blotted for SREBP1. According to the results (Figure 8.11, Lanes 1 to 3), SREBP1 protein (bottom lane) was not detected in HEK293A cells with either treatment. Lanes 4 to 6 (positive control) present whole cell lysates of FLAG-OGFOD1 transfected HEK293A cells and probed with anti-SREBP1. Lane 7 (Negative control) is the coimmunoprecipitation of SREBP1 with empty vector and Lane 8 (Negative control) is the whole cell lysate of HEK293A cells with transfection of empty vector (FLAG-pCR3.1). The first three lanes showed very thin FLAG bands (upper panel) due to limited amount of FLAG-OGFOD1 that was immunoprecipitated by anti-FLAG beads. By comparing the positive controls (Lane 4 to 6) to the negative control (Lane 7), there was no SREBP1N immunoprecipitated by OGFOD1. This result indicated that there may be either no or transient (weak) interaction between SREBP1 and OGFOD1.

\subsection{Novel proteins could interact with OGFOD1}

To identify the novel proteins that associate with OGFOD1, immunoprecipitation of FLAG-OGFOD1 was followed by silver staining of all associated proteins on SDS-PAGE. The Figure 8.12 shows that the results of proteins coimmunoprecipitated with FLAG-OGFOD1. The first lane is the immunoprecipitation from cells transfected with the empty vector (FLAGpCR3.1) as a negative control. The last three lanes are the immunoprecipitations of cells overexpressing FLAG-OGFOD1 and treated with DMOG (normoxic), hypoxia and normoxia treatments. There was one unique band in hypoxic treatment, when compared to normoxia. No new bands appeared during DMOG treatment, but experiments are ongoing to determine unique proteins interacting with OGFOD1 under different conditions. 
Figure 8.11: Western blot of proteins from cells overexpressing FLAG-OGFOD1 and immunoprecipitated using anti-FLAG agarose beads. The Western blot was probed with antiSREBP1 antibodies. Lane 1: IP of wildtype FLAG-OGFOD1 transfected into HEK293A under normoxic conditions $\left(\mathrm{N}, 21 \% \mathrm{O}_{2}\right)$; Lane 2: IP of HEK293A cells transfected with wildtype FLAG-OGFOD1 and treated with hypoxia $\left(\mathrm{H}, 1 \% \mathrm{O}_{2}\right)$ for 48 hours; Lane 3: IP of HEK293A cells transfected with wildtype FLAG-OGFOD1 and treated with DMOG for 48 hours (normoxia); Lane 4: lysates of HEK293A transfected with wildtype FLAG-OGFOD1 under normoxic conditions; Lane 5: lysate of HEK293A transfected with wildtype FLAG-OGFOD1 and treated with hypoxia for 48 hours; Lane 6: lysate of HEK293A transfected with wildtype FLAG-OGFOD1 and treated with DMOG for 48 hours; Lane 7: IP of HEK293A transfected with empty pCR3.1 vector (negative control) for 48 hours under normoxic conditions; Lane 8: lysate of HEK293A transfected with empty pCR3.1 vector (negative control) for 48 hours under normoxic conditions. 
$\begin{array}{llllllll}1 & 2 & 3 & 4 & 5 & 6 & 7 & 8\end{array}$

Wildtype ++++++-

Vector - - - - - -++

IP $\quad+\quad+\quad+-\infty-$

$\begin{array}{lllllllll}\text { Oxygen } & \mathrm{N} & \mathrm{H} & \mathrm{N} & \mathrm{N} & \mathrm{H} & \mathrm{N} & \mathrm{N} & \mathrm{N}\end{array}$

DMOG - $-+-\quad-\quad+-$

FLAG

SREBP1 N 
Figure 8.12: Silver-stained 8\% SDS-PAGE of proteins immunoprecipitating with FLAGtagged mature OGFOD1 overexpressed in HEK293A cells. Lane 1: Precision Plus Protein Standards (BioRad, Missisauga, ON); Lane 2: HEK293A transfected with empty pCR3.1 vector; Lane 3: HEK293A transfected with and overexpressing wildtype FLAG-OGFOD1 and treated with DMOG (normoxia) for 48 hours; Lane 4: wildtype FLAG-OGFOD1 transfected into HEK293A and treated with normoxia for 48 hours; Lane 5: wildtype FLAG-OGFOD1 transfected into HEK293A and treated with hypoxia for 48 hours. 


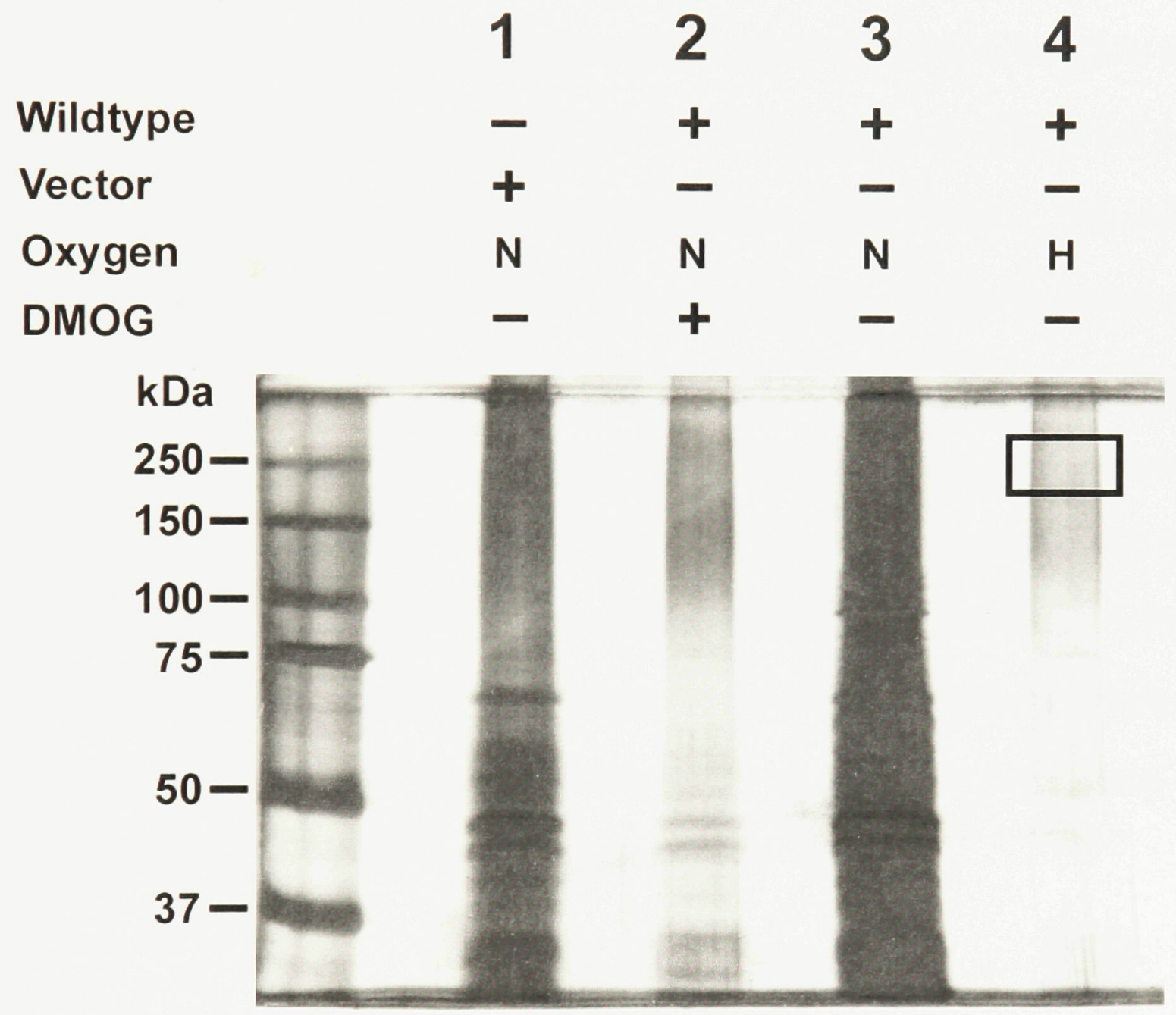




\section{Discussion}

OGFOD1 is a protein that contains two distinct functional domains: an N-terminal hydroxylase (PKHD) regulatory domain and a C-terminal protein-protein interaction/degradation domain. Through a database search of all known proteins (from all organisms for which they are known) for HIF- $\alpha$-like sequences, it was found that the C-terminal domain of OGFOD1 contains the same oxygen-regulatory sequence (LXXLAP) that is found twice in HIF- $\alpha$. This raised the possibility that the stability of this hydroxylase was regulated in an oxygen-dependent manner similar to HIF- $\alpha$. The present study investigated two aspects of OGFOD1: 1) it determined whether the protein had different rates of turnover (i.e. degradation) between normoxic and hypoxic (as well as hypoxic mimetic) conditions and 2) it initiated studies to examine oxygendependent interactions between OGFOD1 and a possible interacting protein (SREBP1) based on evidence found in yeast. Hypoxia and hypoxic mimetics were used to inhibit the activity of the hydroxylase domain of OGFOD1 in order to determine if a) there were direct effects on the protein or b) effects on its potential interaction with SREBP1.

\subsection{Putative hydroxylation site search}

A database search for the LXXLAP peptide sequence revealed over 5,000 different proteins, across multiple species, which contained the sequence. The purpose of this search was to find potential proteins that contain the LXXLAP sequence and can be regulated by oxygen. 
Hydroxylation of this sequence may not necessarily lead to proteolytic degradation of OGFOD1, especially if it lacks sites for attachment of ubiquitin (of which there is no current consensus sequence known), but may lead to a change in function, especially with its potential interaction with SREBP1, given the location of the LXXLAP sequence in the C-terminal degradation domain. HIF- $\alpha$ contains two copies of the LXXLAP sequence which allows HIF- $\alpha$ to be hydroxylated under normoxic conditions and recognized (and bound) by vHL, thereby promoting its degradation. The LXXLAP peptide in HIF- $\alpha$ is conserved amongst most eukaryotic organisms (including Caenorhabditis elegans and Drosophila melanogaster), where the gene has been sequenced. Likewise, the LXXLAP sequence of OGFOD1 was conserved in multiple organisms from which it is known. Since OGFOD1 is a recently characterized protein, there were few organisms from which this protein has been identified. However, most of them that are currently in the database all contained the LXXLAP sequence in the conserved C-terminal domain.

\subsection{Human embryonic kidney (HEK293) cells as a model system}

HEK293A cells represented an ideal model system for observing the SREBP1 protein expression. In the early 70s, HEK293 cells were generated by transformation of cultures of normal human embryonic kidney cells with sheared adenovirus 5 DNA, and the number 293 comes from the product of the $293^{\text {rd }}$ experiment done on this line (Graham et al., 1977). The cell line has been widely-used in cell biology research for years, due to a) it's easy maintenance and 
straightforward culture and b) its high efficiency for transient DNA transfection. Utilizing the transfection method that we did in this study, there is approximately a $99 \%$ transfection efficiency of HEK293 cells if using the manufacturer's protocol (Invitrogen, Carlsbad, CA). Based on the fact that the embryonic cells have the same features as almost all cell types of the body, HEK293 cells are commonly used in the production of therapeutic proteins as well as viruses for gene therapy in the biotechnology industry (Shaw et al., 2002)). These experiments, involve transiently transfecting the gene of interest and analyzing its protein expression. Studies carried out with this cell line includea) protein expression studies (tagged or fusion proteins as well), b) reporter assays for promoter and enhancer function, c) the propogation of adenoviral vectors and d) gene knock down using RNA interference. Thus, HEK293 cells were the model system of choice when studying the function of OGFOD1 under different oxygen regimes as well as its protein-protein interactions.

\subsection{Cell viability}

The MTT assay was performed to assess cell viability under different CHX concentrations. MTT assay is a standard colorimetric assays for measuring the reduction activity of the yellow tetrazolium salt MTT (3-[4,5-dimethylthiazol-2-yl]-2,5-diphenyl tetrazolium bromide ) to a blue-black formazan product by living (but not by dead) cells (Mosmann 1983). In this thesis, different $\mathrm{CHX}$ concentrations were used in conjunction with $\mathrm{CHX}$ to obtain the appropriate concentrations of this translation inhibitor that would block protein synthesis without 
a resulting decrease in cell viability. CHX blocks translational elongation in protein synthesis by interfering with the translocation step (the movement of the two tRNA molecules and mRNA in

relation to the ribosome). Due to the nonselective inhibition of protein synthesis, CHX treatment has profound effects on cells, since all protein syntheses including those critical ones are completely blocked. At a concentration of $0.05 \mathrm{ug} / \mathrm{mL}$, with no effect on cell viability, CHX treatment is able to completely inhibit protein synthesis by 24 hours (Figure 8.6). This concentration was used for subsequent studies involving the inhibition of protein synthesis.

\subsection{OGFOD1 mRNA and protein expression under hypoxic conditions in HEK293A cells}

We analyzed the expression of OGFOD1 in HEK293A cells during chronic hypoxia by Western immunoblotting. OGFOD1 protein levels did not change in response to treatment with hypoxia or hypoxic mimetics compared to normoxia (Figure 8.3). Likewise, there were no significant changes in OGFOD1 protein expression with the hypoxic mimetics cobalt, DFO, and proteasome inhibitor compared to normoxia for the time of treatment (Figure 8.3). Our results indicate that the OGFOD1 protein expression is not oxygen-regulated, and that the LXXLAP sequence within OGFOD1 may not affect its protein expression or turnover.

We utilized qRT-PCR analysis to demonstrate there is no significant change in the level of the OGFOD1 mRNA in HEK293A cells under 6, 24 and 48 hours of hypoxia treatment, compared to normoxia. There was also no significant with 6 hours of proteasome inhibitor 
treatment compared to normoxic controls. Our results conclude that, at different oxygen concentrations and treatment times, the levels of the mRNA of OGFOD1 do not significantly change under from controls for the treatments chosen (Figure 8.4).

To test whether the rate of OGFOD1 degradation may be altered in an oxygen-dependent manner, protein degradation was followed over time in HEK293A cells treated with CHX $(0.05 \mathrm{ug} / \mathrm{mL})$ to inhibit protein translation and overexpressing FLAG-tagged wildtype or mutant OGFOD1, under different oxygen regimes. Approximately $40 \%$ of either wildtype or mutant OGFOD1 is degraded after $48 \mathrm{~h}$ of CHX treatment under both normoxic and hypoxic conditions. As illustrated in Figure 8.7B, the turnover of the mutant protein was same as wildtype under both normoxic and hypoxic conditions. The half-life of FLAG-OGFOD1 was approximately 50 $\mathrm{h}$ (Figure 8.7). OGFOD1 is a long-lived protein, which may not be involved in the ubiquitinproteasome pathway. The ubiquitination of OGFOD1 may not occur as OGFOD1 may lack the sites for ubiquitin attachment. The similar degradation rates for all conditions suggested that the LXXLAP of OGFOD1 may not play a central role in the degradation of OGFOD1. This result shows that the LXXLAP sequence does not correlate with the stability of FLAG-OGFOD1 under either normoxic or hypoxic conditions.

Our results for mammalian OGFOD1 are in contrast with yeast Ofd1 which is affected by oxygen concentration at both mRNA and protein levels (Hughes and Espenshade, 2008). There may be a number of reasons for the differences observed between the homologous proteins in the two different organisms. First, as shown in Figure 8.2, the human and $S$. pombe proteins have only $22 \%$ identity (37\% similarity). Significant differences between the two proteins may mean that they fold quite differently and that the LXXLAP sequence of the C-terminus of OGFOD1 
may be inaccessible to its N-terminal hydroxylase. Since a validated structure for OGFOD1 currently does not exist (x-ray crystallography, solution NMR), it remains unknown if this is the case. Second, there is no known mammalian equivalent of yeast Nro1, the inhibitor protein of Ofd1 which may potentially associate with Ofd1 under hypoxic conditions (i.e. when the Cterminus of Ofd1 is not hydroxylated). If the association of Nro1 provides some stability to Ofd1, then its association under hypoxia may result in increased levels of Ofd1, at least at the level of the protein. It is currently unknown in the yeast system whether the N-terminal hydroxylase of Ofd1 hydroxylates its own C-terminal or Nro1. Third, fission yeast lacks the equivalent of mammalian vHL, the recognition subunit of the mammalian E3 ubiquitin ligase. If OGFOD1 is degraded by the LXXLAP signal, this would be unique to higher eukaryotes. Fourth, OGFOD1 may lack the sites of ubiquitin attachment. It is unknown if Ofd1 is a protein that can be ubiquitinated. The differences between these two systems merit further investigation.

\subsection{SREBP1 and OGFOD1}

It has previously been reported that an interaction occurs between fission yeast Ofd1 and Sre1. Under normoxic conditions, the C-terminal degradation domain of Ofd1 interacts with Sre1N, resulting in its degradation (Figure 6.9). As well, the increase in both Ofd $1 \mathrm{mRNA}$ and protein under low oxygen conditions in S. pombe required Srel (Espenshade and Hughes, 2008). We wished to test the potential interaction between the mammalian homologues of Ofd1 and Sre1 in yeast. In HEK293A cells, as shown by the results in Figure 8.9, hypoxia upregulated 
SREBP1N, but downregulated SREBP1P. The increase in SREBP1N, in both untransfected and transfected cells, was approximately 2-fold. Therefore, overexpression of OGFOD1 does not significantly change the expression of precursor and mature forms of SREBP1. Thus, interaction between OGFOD1 and SREBP1N or SREBP1P, according to this study, did not occur. One explanation for this would be that hypoxia stimulates HIF-induced production of SREBP1N. HIF promotes the gene expression of SCAP, the protein responsible for SREBP1P cleavage, and an increase in SCAP would accelerate the transport process of SREBP1P from the ER to the Golgi complex and stimulate the release of active SREBP1N (Li et al, 2006). Our results strongly support this mechanism; we observed more mature SREBP1N and less SREBP1P under hypoxia, indicating that the increase in SREBP1N was mainly due to increased proteolysis of SREBP1P rather than any other mechanism such as increased gene expression of SREBP1.

A doublet band was seen for SREBP1N under hypoxic conditions that was not seen in normoxic conditions (Figure 8.9A) This doublet band was seen only with endogenous and overexpressed wildtype OGFOD1 and was not seen with mutant OGFOD1. This would suggest that there is an oxygen-dependent posttranslational modification of, specifically, the mature form of SREBP1 and not the immature form. This modification, for example, may be phosphorylation. Since the doublet band of SREBP1N was not seen with 24 hours of treatment (Figure 8.9C), this modification may only occur under long-term hypoxic conditions. Further investigation is warrented to determine what the oxygen-dependent modification of SREBP1N is and how mutation of the LXXLAP sequence of OGFOD1 can affect this.

Furthermore, we wanted to inhibit the PKHD domain of OGFOD1 by adding DMOG and cobalt chloride and compare the expression levels of SREBP1N and SREBP1P in FLAGOGFOD1 transfected and nontransfected cells. DMOG and cobalt chloride are specific and 
nonspecific inhibitors of prolyl hydroxylases respectively. Therefore, under such conditions, the SREBP1N levels would be expected to increase significantly. In nontransfected cells, endogenous SREBP1N was increased with both DMOG and $\mathrm{CoCl}_{2}$ treatments (Figure 8.10). At the same time, SREBP1P significantly decreased with DMOG and $\mathrm{CoCl}_{2}$ compared to normoxia. These results suggested that, under hypoxic mimetic treatments, the precursor (inactive) form of SREBP1 is cleaved to become active (mature) form. However, when comparing the fold increase of SREBP1N between untransfected and transfected HEK293A cells, the PKHD domain of OGFOD1 does not appear to have an effect on SREBP1 expression in comparison to the endogenous expression of SREBP1.

These results differ from those found for Ofd1 in yeast. In fission yeast, Ofd1 gene and protein expression is regulated by oxygen. Ofd 1 accelerates degradation of Sre $1 \mathrm{~N}$ in the presence of oxygen, but under low oxygen Ofd1 is inhibited and Sre1N accumulates. Nro1, a novel yeast protein that does not have any known mammalian homologue, stabilizes Sre1N and inhibits Ofd1 by directly binding to its C-terminus (Espenshade, 2008). The mechanism for this has not fully been determined. The possibility exists that $S$. pombe Nrol is hydroxylated in an oxygendependent manner. Examining the amino acid sequence of Nro1, multiple amino acids could be hydroxylated by hydroxylases such as the N-terminus of Ofd1 (Figure 9.1). The lack of Nro1 in mammalian cells may explain the differences between the functions of OGFOD1 in mammals and Ofd1 in yeast.

Human OGFOD1 was N-terminally FLAG-tagged, expressed and immunoprecipitated from HEK293A cells. Immunoprecipitates were analyzed by Western blot for SREBP1 (Figure 8.11). Neither SREBP1N nor SREBP1P coprecipitated with FLAG-OGFOD1 protein under normoxic, hypoxic or hypoxic mimetic treatments. This result suggests that OGFOD1 does not 
strongly interact with either SREBP1N or SREBP1P, but does not rule out weak or transitory interactions between the two proteins possibly occurring. Future experiments will involve reversible crosslinkers to try to capture any weak interaction between OGFOD1 and SREBP1. SDS-PAGE run on whole cell extracts and immunoprecipitations (Figure 8.12) from HEK293A overexpressing wildtype FLAG-OGFOD1 show that there are two bands (red boxes) differentially expressed under hypoxic mimetics comparing to normoxia. These proteins could potentially interact with OGFOD1 under hypoxia and will be isolated and identified by mass spectrometry.

\subsection{Future directions}

Future studies could examine the stability of SREBP1 under hypoxia in the absence of OGFOD1; OGFOD1 mRNA levels could be knocked down by transfection with siRNA. Also, point mutations in the PKHD domain of OGFOD1 that abolish iron or cofactor binding site in PKHD domain of OGFOD1 could differentially affect SREBP1N stability between normoxic and hypoxic conditions. These experiments would elucidate the differences seen in this study between SREBP1 stability with endogenous and overexpressed OGFOD1 in mammalian cells. 
Figure 9.1: Amino acid sequence of Nro1 from S. pombe and S.cerevisiae. The highlighted amino acids with different colors are the amino acids that could potentially be hydroxylated by proline (blue), asparagine (N) and aspartate (D) hydroxylases. 
Schizosaccharomyces pombe (fission yeast)

MIGRRPQGLRAAASLKKQQQLEKQKQEASYELSGNSSPSKENGSENVDNGEMEDETML VYTEEDNISQL WGL YEMSREKLENDDIDASVSLVFGTIHEADRILRNTEDISTLPKDFHA AYSSALLAVSELFEIAQKRLKETNTEESYIDAAIERAQLGLDAPGNESRLFLALARAYLE KVRVLVWRHDNEESLANIPVTQLVNPYIEKAIQYLRPLAQDSTEYFDALTPDSLRPLYIL SSYLFQFGDQFSEAFLLDVCSIITAL WLKSVVDPNTPAYYKLIAQEAVLNNYTTFAEYYM DLLDNSESNVDDLINKASSWLNNSVDTWNVIYTLDKSPERLLKLADIKMDLAQIVQDEA SQDNYLKEACNAIKEAQGSGVELSPDYVEFVEAYSA

Saccharomyces cerevisiae (Baker's yeast)

MAKRPLGLGKQSREKKRKVESVEKKSDEPSRESTPVRSQMSVELDDDADLDDELAQLK GLWSKYFHSDRDDEYVLNGIVHECDRLLRLSEEDKEIKKTLNDIFHGIYALALSELTIFK AGDEEATEEKRKKDVSSFFESAIERVELGLSHFPESQFLKLVLAKIIFQRIPLEYISNLHLK SKDKKLDLVGQLEHGKKHFSIYENDTEFTFEILQMVNDLLDIVENFGREQSIQEGIDSDN EEEEELIDIELEPEHPVYPLQQSLEANYEWLRNHFDKLLDNTNTDVKIYASIANTLGELYL KKAEEPSKVFLSLQYDDGGSEKVSDKEAKNAQETALKHTKKALEYLEKAKLEDDPDT WVQVAEAYIDLGNLLDNESAEQEEAYKTAEEILGKANKASHGKFQDVLDNFLQG* 


\section{References}

Abu-Farha, M., Niles, J., Willmore, W.G. 2005. Erythroid-specific 5-aminolevulinate synthase protein is stabilized by low oxygen and proteasomal inhibition. Biochem. Cell Biol. 83: 620-630.

Adam, J. 2003. Potential for proteasome inhibition in the treatment of cancer. DTT. 8: 307315.

Bengoechea-Alonso, M., Ericsson, J. 2009. A phosphorylation Cascade controls the degradation of active SREBP1. J. Biol. Chem. 284: 5885-5895.

Bergeron, M., Yu, A.Y., Solway, K.E., Semenza, G.L., Sharp, F.R. 1999. Induction of hypoxiainducible factor-1 (HIF-1) and its target genes following focal ischaemia in rat brain. Euro. J. Neurosci. 11: 4159-4170

Boeckmann, B., Bairoch, A., Apweiler, R., Blatter, M.C., Estreicher, A., Gasteiger, E., Martin, M.J., Michoud, K., O’Donova, C., Phan, I., Pilbout, S., Schneider, M. 2003. The SWISSPROT protein knowledgebase and its supplement TrEMBL in 2003. Nucleic Acids Res. 31: $365-370$

Brown, M.S., and Goldstein, J.L. 1997. The SREBP pathway: regulation of cholesterol metabolism by proteolysis of a membrane-bound transcription factor. Cell. 89: 331-340. 
Cho, H., Park, H., Yang, E.G. 2005. A fluorescence polarization-based interaction assay for hypoxia-inducible factor prolyl hydroxylases. Biochem. Biophys. Res. Commun. 337: 275280.

Chaudhary J., Skinner, M.K. 1999. Basic helix-loop-helix proteins can act at the E-box within the serum response element of the c-fos promoter to influence hormone-induced promoter activation in Sertoli cells. Mol. Endocrinol. 13: 774-786.

Chun, Y.S., Kim, M.S., Park, J.W. 2002. Oxygen-dependent and independent regulation of HIF1 alpha. J. Korean Med. Sci. 17: 581-588

Eberle, D., Hegarty, B., Bossard, P., Ferre, P., Foufelle, F. 2004. SREBP transcription factors: master regulators of lipid homeostasis. Biochimie. 86: 839-848.

Epstein, A.C.R., Gleadle, J.M., Mcneil, L.A., Hewitson, K.S., O'Rourke, J., Mole, D.R., Mukherji, M., Metzen, E., Wilson, M.I., Dhanda, A., Tian, Y.M., Masson, N., Hamilton, D.L., Jaakkola, P., Barstead, R., Hodgkin, J., Maxwell, P.H., Pugh, C.W., Schofield, C.J., Ratcliffe, P.J. 2001. C.elegans EGL-9 and mammalian homologs define a family of dioxygenases that regulate HIF by prolyl hydroxylation. Cell. 107: 43-54.

Furuta, E., Pai, S.K., Zhan, R., Bandyopadhyay, S., Watabe,, M., Mo, Y.Y., Hirota, S., Hosobe, S., Tsukada, T., Miura, K., Kamada, S., Saito, K., Iiizumi, M., Liu, W., Ericsson, J., Watabe, K. 2008. Cancer Res. 68: 1003-1011. 
Fraisl, P., Aragones, J., Carmeliet, P. 2009. Inhibition of oxygen sensors as a therapeutic strategy for ischaemic and inflammatory disease. Nature Reviews. 8: 139-152.

Goldstein, J.L., Rawson, R.B., and Brown, M.S. 2002. Mutant mammalian cells as tools to delineate the sterol regulatory element-binding protein pathway for feedback regulation of lipid synthesis. Arch. Biochem. Biophys. 397: 139-148.

Graham, F.L., Smiley, J., Russell, W.C., Nairn, R. 1977. Characteristics of a human cell line transformed by DNA from human adenovirus type 5. J. Gen. Virol. 36: 59-74.

Horton, J.D., Goldstein, J.L., Brown, M.S. 2002. SREBPs: activators of the complete program of cholesterol and fatty acid synthesis in the liver. J. Clin. Invest. 109: 1125-1131.

Hua, X., Wu, J., Goldstein, J.L., Brown, M.S., Hobbs, H.H. 1995. Structure of the human gene encoding sterol regulatory element binding protein-1 (SREBF1) and localization of SREBF1 and SREBF2 to chromosomes 17p11.2 and 22q13. Genomics. 25: 667-673.

Huang, J., Zhao, Q., Mooney, S.M., Lee, F.S. 2002. Sequence determinants in hypoxia-inducible factor-1 $\alpha$ for hydroxylation by the prolyl hydroxylases PHD1, PHD2 and PHD3. J. Biol. Chem. 277: 39792-39800. 
Huang, L.E., Gu, J., Schau, M., Bunn, H.F. 1998. Regulation of hypoxia-inducible factor $1 \alpha$ is mediated by an $\mathrm{O}_{2}$-dependent degradation domain via the ubiquitin-proteosome pathway. Proc. Natl. Acad. Sci. USA. 95: 7987-7992.

Hughes, A.L., Todd, B.L., Espenshade, P.J. 2005. SREBP pathway responds to sterols and functions as an oxygen sensor in fission yeast. Cell. 120: 831-842.

Hughes, B.T., Espenshade, P.J. 2008, Oxygen-regulated degradation of fission yeast SREBP by Ofd1, a prolyl hydroxylase family member. EMBO J. 83: 1-11.

Jay, D., Horton, J.L. Goldstein, J.L., Brown, M.S. 2002. SREBPs: activators of the complete program of cholesterol and fatty acid synthesis in the liver. J. Clin. Invest. 109: 1125-1131.

Koivunen, P., Hirsila, M., Gunzler, V., Kivirikko, K.I., Myllyharju, J. 2004. Catalytic properties of the asparaginyl hydroxylase (FIH) in the oxygen sensing pathway are distinct from those of its prolyl 4-hydroxylases. J. Biol. Chem. 279: 9899-9904.

Krogan, N.J., et al. 2006. Global landscape of protein complexes in the yeast Saccharomyces cerevisiae. Nature 440: 637-643.

Lee, C.Y.S., Stewart, E.V., Hughes, B.T., Espenshade, P.J. 2009. Oxygen-dependnet binding of Nro1 to the prolyl hydroxylase Ofd1 regulates SREBP degradation in yeast. EMBO J. 28: $135-143$. 
Lee, K., Burgoon, L.D., Lamb, L., Dere, E., Zacharewski, T.R., Hogenesch, J.B. and LaPres, J.J., 2006. Identification and characterization of genes susceptible to transcriptional cross-talk between the hypoxia and dioxin signalling cascades. Chem. Res. Toxicol. 19: 1284-1293.

Li, J., Thorne, L.N., Punjabi, N.M., Sun, C.-K., Schwartz, A.R., Smith, P.L., Marino, R.L., Rodriguez, A., Hubbard, W.C., O'Dounell, C.P., Polotsky, V.Y. 2005. Intermittent hypoxia induces hyperlipidemia in lean mice. Circ. Res. 97: 698-706.

Li, J., Bosch-Marce, M., Nanayakkara, A., Savransky, V., Fried, S.K., Semenza, G.L., Polotsky, V.Y., 2006 Altered metabolic responses to intermittent hypoxia in mice with partial deficiency of hypoxia-inducible factor-1 $\alpha$, Physiol. Genomics 25: 450-457.

Masson, N. and Ratcliffe, P.J. 2003. HIF prolyl and asparaginyl hydroxylases in the biological response to intracellular $\mathrm{O}_{2}$ levels. J. Cell Sci. 116: 3041-3049

McDonough, M.A. 2006 Cellular oxygen sensing: crystal structure of hypoxia-inducible factor prolyl hydroxylase (PHD2). Proc. Natl Acad. Sci. 103: 9814-9819.

Minamishima, Y.A., Moslehi, J., Bardeesy, N., Cullen, D., Bronson, R.T., Kaelin Jr., W.G. 2008. Somatic inactivation of the PHD2 prolyl hydroxylase causes polycythemia and congestive heart failure. Blood. 111: 3236-3244. 
Miserez, A.R., Cao, G., Probst, H.H. 1997. Structure of the human gene encoding sterol regulatory element binding protein-2 (SREBF2). Genomics. 40: 31-40

Mircea, I., Kondo, K., Yang, H., Kim, W., Valiando, J., Ohh, M., Salic, A., Asara, J.M., Lane, W.S., and Kaelin Jr., W.G. 2001. HIF $\alpha$ targeted for VHL-mediated destruction by proline hydroxylation: implications for $\mathrm{O}_{2}$ sensing. Science. 292: 464-468.

Mosmann, T. 1983. Rapid colorimetric assay for cellular growth and survival: application to proliferation and cytotoxicity assays. J. Immunol. Methods. 65: 55-63.

Murre, C., Bain, G., van Dijk, M.A., Engel. I., Furnari, B.A., Massari, M.E., Matthews, J.R., Quong, M.W, Rivera, R.R., Stuiver, M.H. 1994. Structure and function of helix-loop-helix proteins. Biochim. Biophys. 2: 129-135.

Nangaku, M., Kojima, I., Tanaka, T., Ohse, T., Kato, H., Fujita, T. 2006. Novel drugs and the response to hypoxia: HIF stabilizers and prolyl hydroxylase. Recent Patents Cardiovasc. Drug Discov. 1: 129-139.

Naranjo-Suárez, S., Castellanos, M.C., Álvarez-Tejado, M., Vara, A., Landazuri, M.O., del Peso, L. 2003. Down-regulation of hypoxia-inducible factor-2 in PC12 cells by nerve growth factor stimulation. J. Biol. Chem. 278: 31895-31901. 
Neer, E.J., Schmidt, C.J., Nambudripad, R., Smith, T.F. 1994. The ancient regulatory-protein family of WD-repeat proteins. Nature. 371: 297-300.

Pfaffl, M.W. 2001. A new mathematical model for relative quantification in real-time RT-PCR. Nucleic. Acid. Res. 29: 2002-2007.

Ponting, C.P., Aravind, L. 1997. PAS: a multifunctional domain family comes to light. Curr. Biol. 7: R674-R677.

Reverte, C.G., Ahearn, M.D., Hake, L.E. 2001. CPEB degradation during Xenopus oocyte maturation requires a PEST domain and the 26S proteasome. Dev. Biol. 231: 447-58.

Rogers, S., Wells, R., Rechsteiner, M. 1986. Amino acid sequences common to rapidly degraded proteins: the PEST hypothesis. Science. 234: 364-368.

Safran, M., Kaelin, J.r. 2003. HIF hydroxylation and the mammalian oxygen-sensing pathway. J. Clin. Invest. 111: 779-783.

Sato, R. 2008. SREBPs: protein interaction and SREBPs. FEBS Journal. 276: 622-627.

Schofield, C.J., Ratcliffe, P.J. 2004. Oxygen sensing by HIF hydroxylases. Nature Rev. Mol. Cell Biol. 5: 343-354. 
Semenza, G. 1999. Regulation of mammalian $\mathrm{O}_{2}$ homeostasis by hypoxia-inducible factor 1 . Annu. Rev. Cell Dev. Biol. 15: 551-578.

Semenza, G. 2002. Signal transduction to hypoxia-inducible factor-1. Biochem. Pharm. 64: 993998.

Semenza, G. 2007. Life with oxygen. Science. 318: 62-64.

Safran, M. and Kaelin Jr., W.G. 2003. HIF hydroxylation and the mammalian oxygen-sensing pathway. J. Clin. Invest. 111: 779-783.

Shaw, G., Morse, S., Ararat, M., Graham, F.L. 2002. Preferential transformation of human neuronal cells by human adenoviruses and the origin of HEK 293 cells. FASEB J. Express. 16: $869-871$.

Shumway, S.D., Maki, M., Miyamoto, S. 1999. The PEST domain of IkappaBalpha is necessary and sufficient for in vitro degradation by mu-calpain. J. Biol. Chem. 274: 30874-30881.

Shimomura, I., Shimano, H., Horton, J.D., Goldstein, J.L., and Brown, M.S. 1997. Differential expression of exons $1 \mathrm{a}$ and $1 \mathrm{c}$ in mRNAs for sterol regulatory element binding protein-1 in human and mouse organs and cultured cells. J. Clin. Invest. 99: 838-845. 
Takeda, K. and Yanagida, M. 2005. Regulation of nuclear proteasome by Rhp6/Ubc2 through ubiquitination and destruction of the sensor and anchor Cut8. Cell. 122: 393-405.

Taylor, B.L and Zhulin, I.B. 1999. PAS domains: internal sensors of oxygen, redox potential and light. Microbiol. Mol. Biol. Rev. 63: 479-506.

Todd, B.L., Stewar, E.V., Burg, J.S., Hughes, A.L., Espenshade, P.J. 2006. Sterol regulatory element binding protein is a principal regulator of anaerobic gene expression in fission yeast. Mol. Cell. Biol. 26: 2817-2831.

Wall, L. 1987-2001. Perl for Windows v.5.6.1.

Wang, G.L., Jiang, B.H., Rue, E.A., Semenza, G.L. 1995. Hypoxia-inducible factor 1 is a basichelix-loop-helix-PAS heterodimer regulated by cellular $\mathrm{O}_{2}$ tension. Proc. Natl. Acad. Sci. 92: $5510-5514$.

Wenger, R.H. 2002. Cellular adaptation to hypoxia: $\mathrm{O}_{2}$-sensing protein hydroxylases, hypoxiainducible transcription factors, and $\mathrm{O}_{2}$-regulated gene expression. FASEB J. 16: 1151-1162

You, M. and Crabb, D.W. 2004. Molecular mechanisms of alcoholic fatty liver: role of sterol regulatory element-binding proteins. Science Direct. 24: Issue 1. 